\title{
The role of brain barriers in fluid movement in the CNS: is there a 'glymphatic' system?
}

\author{
N. Joan Abbott ${ }^{1}\left(\mathbb{D} \cdot\right.$ Michelle E. Pizzo $^{2,3} \cdot$ Jane E. Preston ${ }^{1} \cdot$ Damir Janigro $^{4,5} \cdot$ Robert G. Thorne $^{2,3,6,7,8,9}$
}

Received: 6 November 2017 / Revised: 16 January 2018 / Accepted: 24 January 2018 / Published online: 10 February 2018

(C) The Author(s) 2018. This article is an open access publication

\begin{abstract}
Brain fluids are rigidly regulated to provide stable environments for neuronal function, e.g., low $\mathrm{K}^{+}, \mathrm{Ca}^{2+}$, and protein to optimise signalling and minimise neurotoxicity. At the same time, neuronal and astroglial waste must be promptly removed. The interstitial fluid (ISF) of the brain tissue and the cerebrospinal fluid (CSF) bathing the CNS are integral to this homeostasis and the idea of a glia-lymph or 'glymphatic' system for waste clearance from brain has developed over the last 5 years. This links bulk (convective) flow of CSF into brain along the outside of penetrating arteries, glia-mediated convective transport of fluid and solutes through the brain extracellular space (ECS) involving the aquaporin-4 (AQP4) water channel, and finally delivery of fluid to venules for clearance along peri-venous spaces. However, recent evidence favours important amendments to the 'glymphatic' hypothesis, particularly concerning the role of glia and transfer of solutes within the ECS. This review discusses studies which question the role of AQP4 in ISF flow and the lack of evidence for its ability to transport solutes; summarizes attributes of brain ECS that strongly favour the diffusion of small and large molecules without ISF flow; discusses work on hydraulic conductivity and the nature of the extracellular matrix which may impede fluid movement; and reconsiders the roles of the perivascular space (PVS) in CSF-ISF exchange and drainage. We also consider the extent to which CSF-ISF exchange is possible and desirable, the impact of neuropathology on fluid drainage, and why using CSF as a proxy measure of brain components or drug delivery is problematic. We propose that new work and key historical studies both support the concept of a perivascular fluid system, whereby CSF enters the brain via PVS convective flow or dispersion along larger caliber arteries/arterioles, diffusion predominantly regulates CSF/ISF exchange at the level of the neurovascular unit associated with CNS microvessels, and, finally, a mixture of CSF/ISF/waste products is normally cleared along the PVS of venules/veins as well as other pathways; such a system may or may not constitute a true 'circulation', but, at the least, suggests a comprehensive re-evaluation of the previously proposed 'glymphatic' concepts in favour of a new system better taking into account basic cerebrovascular physiology and fluid transport considerations.
\end{abstract}

Keywords Blood-brain barrier · Cerebrospinal fluid · Interstitial fluid · Glymphatic $\cdot$ Extracellular space $\cdot$ Perivascular space

N. Joan Abbott

joan.abbott@kcl.ac.uk

$\triangle$ Robert G. Thorne

robert.thorne@wisc.edu

1 Faculty of Life Sciences and Medicine, Institute of Pharmaceutical Science, King's College London, Franklin Wilkins Building 3.82, 150 Stamford St, London SE1 9NH, UK

2 Division of Pharmaceutical Sciences, University of Wisconsin-Madison School of Pharmacy, Madison, WI, USA

3 Clinical Neuroengineering Training Program, University of Wisconsin-Madison, Madison, WI, USA
4 Flocel Inc., Cleveland, OH, USA

5 Department of Physiology, Case Western Reserve University, Cleveland, OH, USA

6 Neuroscience Training Program, University of Wisconsin-Madison, Madison, WI, USA

7 Cellular and Molecular Pathology Graduate Training Program, University of Wisconsin-Madison, Madison, WI, USA

8 Institute for Clinical and Translational Research, University of Wisconsin-Madison, Madison, WI, USA

95113 Rennebohm Hall, 777 Highland Avenue, Madison, WI 53705, USA 


\section{Introduction}

The brain is the most important regulatory site in the body, coordinating the input from sensory endings in all organs and the appropriate motor output in response, taking into account learning and memory, and allowing for running repairs to maintain active function. The neurons responsible for this coordination and their synaptic interconnections use transmembrane ionic gradients and movements to generate essential potential changes, including action potentials that propagate along axons, and synaptic potentials generated in post-synaptic membranes by transmitters released from the presynaptic neuron. Generation of the ionic currents responsible requires an extremely stable ionic microenvironment [2]. Homeostasis of the neural microenvironment depends on the effective separation of this environment from the blood while allowing efficient exchange of essential gases, nutrients and waste products of metabolism, and efficient removal of larger waste products and cell debris. The housing of the delicate brain tissue within the skull provides some mechanical protection from trauma, but 'buffer zones' allowing the brain to float in a suitable fluid are also needed. The modern mammalian brain achieves all of these by compartmentalisation that allows dynamic exchange across key interfaces.

The surface of the brain is protected by three layers of 'meninges', the tough outer dura, then the 'leptomeninges' formed by the arachnoid layer and the pia [44]. The mammalian central nervous system is immersed in cerebrospinal fluid (CSF), a complex secretion primarily from circulating plasma, divided unequally between ventricular sites inside the brain (the connected lateral, third, and fourth ventricles) and extraventricular sites outside the brain and spinal cord (the subarachnoid spaces that typically contain most of the CSF) [44, 138, 177]. Interstitial fluid (ISF) fills the narrow 40-60 nm wide extracellular space (ECS) between neurons and glia $[171,180]$. While ISF is often regarded as similar in composition to CSF, this may be strictly correct only at ventricular and pial brain/spinal cord surface interfaces, because (1) diffusion increasingly limits exchange with distance from these interfaces and (2) a number of proteins and polysaccharides, e.g., extracellular matrix, are bound to cells and other ECS constituents and, therefore, not available for free exchange with the relatively cell-free CSF $[171,192]$.

\section{History of CSF generation and flow}

Ancient views on the role of CSF have ranged from symptoms of disease, to the seat of the soul or spirit. The ethereal spirit was thought to be formed in the brain and processed to a liquor vitalis, flowing to the rest of the body along nerves and spinal cord (Galenus of Pergamon $130-201 \mathrm{AD}$, in [13]). What is astounding to us now is that the brain itself was thought to have little value, beyond acting as a conduit for CSF and maintaining the fluid. This idea became so culturally embedded, despite reservations by scientists such as Vesalius in the sixteenth century, that Shakespeare writes "a foolish ... spirit, ...full of ... objects, ideas, apprehensions, ... begot in the ventricles of memory, nourished in the womb of the pia mater" when describing his school master in 'Love's Labour's Lost' [13].

Centuries of anatomists including Cotugno (1764), Magendie (1842), and von Luschka (1870) [46] demonstrated the connections between the lateral ventricles and subarachnoid space, the latter two giving their names to the anatomical foramina connecting these spaces. Although they could not then discern the direction of CSF flow, important progress was made. However, it was not until 1891 when Quincke developed lumbar puncture to sample CSF from living subjects [116] that the modern study of CSF dynamics, production, and composition began, opening the way to new tools for diagnosis of brain diseases and treatment progress.

In the early twentieth century, experimental physiologists took this further, identifying a location for CSF secretion as the choroid plexuses (CPs) and the source of fluid as choroidal blood. By removing one lateral ventricle $\mathrm{CP}$ in the dog and blocking outflow via the foramina of Monro and the aqueduct of Sylvius, Dandy in 1919 [40] observed the ventricle containing the plexus expanded, while the other decreased in size, concluding that the $\mathrm{CP}$ was actively secreting CSF. More direct evidence for choroidal blood as a source of the CSF was given by Welch in 1963 [187] who showed that the haematocrit of blood from the main choroidal vein was higher than in the anterior choroidal artery, suggesting loss of plasma volume as the blood passed through the plexus. The rate of CSF secretion has since been estimated for several mammalian species using a variety of techniques. Despite the obvious caveats when comparing rates between species, CSF secretion rate per unit weight of $\mathrm{CP}$ is quite comparable, between 0.2 and $0.6 \mu \mathrm{l} / \mathrm{min} / \mathrm{g}$ [45].

At the same time as Welch, Ames et al. [5] observed freshly secreted CSF from exposed CPs which had been covered in oil. This method allowed newly secreted CSF collection and analysis, showing that its composition was similar to bulk CSF, but quite different from a simple plasma filtrate. For example, CSF has a higher $\mathrm{Na}^{+}$and $\mathrm{Cl}^{-}$concentration compared to plasma, but is lower in $\mathrm{K}^{+}, \mathrm{Ca}^{2+}$, glucose, amino acids, and urea [41]. Notably, CSF has little protein, less than $0.5 \%$ of plasma levels [39]. The relative paucity of complex molecules led to the idea of CSF acting as a 'sink' [42] into which brain metabolites and waste 
products could flow down their concentration gradient and be removed with the normal drainage of CSF. Examples include metabolites of serotonin and histamine flowing from brain into CSF for disposal [10, 140].

\section{Pulsatile flow of CSF}

With the advent of modern imaging techniques, especially phase contrast and real-time MRI, it is now possible to visualise CSF flow in the intact CNS and understand its circulation in more detail. These techniques are not without methodological issues [22], but the weight of evidence favours a second-to-second pulsatile movement of CSF through the ventricular system, which also changes throughout the day. Early MRI studies by Nilsson et al. [129] observed pulsatile CSF flow through the cerebral aqueduct, and CSF velocity varied with cardiac cycle. During cardiac systole, CSF flowed approximately $8 \mathrm{~mm} / \mathrm{s}$ toward the posterior brain (caudally), then gently back at $5 \mathrm{~mm} / \mathrm{s}$ to the anterior brain (cranially) during cardiac diastole. Although the net direction of flow is toward the posterior brain, such pulsatility would act to mix CSF contents between ventricles and encourage the sink action of CSF (illustrative video can be seen at Wikimedia creative commons; [49]). Because peak CSF pulse velocity corresponds with the elevated systolic blood pressure during each heart beat, the increased volume and pressure of blood entering the brain tissue and plexuses is thought to cause transient tissue swelling, squeezing the ventricles and subarachnoid space (SAS), mixing and moving the bulk CSF toward drainage sites. Mathematical models developed by Linninger and colleagues to inform a mechanistic understanding of the relationship between vascular pulsation and CSF flow correlate well with in vivo data from healthy humans and help explain in more detail the clinical observation that CSF flow reversal is seen first in the cisterns, then in the lateral ventricles during the cardiac cycle [170]. Their models predict that vascular expansion following cardiac systole occurs first at the base of the brain, so reversing the flow of cisternal CSF, followed by dilation of arterioles in brain parenchyma, compressing both subarachnoid space and lateral ventricles and displacing fluid toward the spinal canal. Contributing to this rhythm, respiration adds to pulsatility, but at a lower frequency [54]. Spector et al. [166] suggest that during anaesthesia, with slower and shallower breathing, this mixing effect would be reduced.

Superimposed on these acute pulses is a circadian or diurnal rhythm. In children with hydrocephalus and an intrathecal catheter, circadian rhythms are seen in intracranial pressure, achieving twice the pressure during slow-wave sleep compared to the awake state [149]. In adult volunteers (25-32 years), maximal CSF production was estimated as
$42 \pm 2 \mathrm{ml} / \mathrm{h}$ at 02:00 in the middle of the sleep cycle (range $35-48 \mathrm{ml} / \mathrm{h} n=6$ ), whereas the minimum was $12 \pm 7 \mathrm{ml} / \mathrm{h}$ at 18:00 in the afternoon [129]. This gives a range of around 300-1000 ml CSF produced per day, depending on the time of day that the measurements are made. A similar diurnal rhythmicity is also seen in rat CSF [100], and interestingly, there is a parallel change in blood-brain barrier (BBB) P-glycoprotein efflux transport function, which is increased during the waking period, suggesting a wider circadian control of brain barriers and fluids consistent with the majority of physiological functions.

Refinements in MRI and improved resolution have made CSF imaging an invaluable tool in diagnosis and treatment supervision and carefully designed studies have confirmed these early results. Overall, the net CSF flow in adults is through the ventricles to the basal subarachnoid spaces [12, 166].

\section{The need for CSF_brain ISF exchange}

The exchange between CSF and ISF is the subject of intense and technically difficult investigation, either in the context of CSF as a route for drug delivery to brain, or to understand removal of waste products and pathological markers. However, what might be the physiological purpose of this fluid exchange, beyond acting as a sink?

The requirement for molecular transfer between CSF and brain ISF can be illustrated by compounds which are required by the CNS, but do not significantly enter brain from the systemic circulation across the brain endothelium forming the BBB. These fall into three categories based on the origin of the molecules.

First, compounds synthesised by one region of the brain may require wider CNS distribution and use CSF pathways to achieve this, for example, melatonin and vasopressin [147, 152, 153]. Melatonin, an antioxidant which also sets the body's circadian rhythm via the suprachiasmatic nucleus ( $\mathrm{SCN}$ ), requires CSF for its distribution from synthesis in the pineal gland to multiple CNS sites. Melatonin is secreted into the third ventricle (3V) CSF, which is in direct contact with the pinealocytes; at night, during peak melatonin synthesis, the CSF concentration is $15-20 \times$ that of plasma $[110,174]$. The hormone is transferred by CSF to the SCN, other hypothalamic regions, the hippocampus, and choroid plexuses, where there are high affinity MT1 receptors [56]. Lateral ventricle (LV) melatonin concentrations have been reported to be far lower than $3 \mathrm{~V}$ melatonin concentrations; this observation has been used in part to argue that $3 \mathrm{~V}$ melatonin is not coming from recirculation via the plasma and choroid plexuses but rather through direct secretion into the pineal recess $[159,183]$. Indeed, in sheep, brain melatonin concentration close to the third ventricle walls and 
aqueduct of Sylvius is double that of plasma [110], penetrating $8-10 \mathrm{~mm}$ into brain as the concentration gradually falls.

In a second category are compounds of the systemic circulation that primarily enter CNS across the CPs into CSF, for example, vitamin C and folate [164, 165]. Vitamin C crosses CPs via the sodium vitamin $\mathrm{C}$ transporter 2 (SVCT2, solute carrier family Slc23a1), which is absent at the BBB in health, although may be expressed after stroke [67]. Oxidized vitamin $C(\approx 10 \%$ of total vitamin $C$ ) may use the GLUT1 transporter [130], but there is little functional contribution in SVCT2 knockout mice, where CNS vitamin C is not detectable and mice die soon after birth [163]. In wildtype animals, CSF and brain vitamin $\mathrm{C}$ are around $6 \times$ higher than plasma (200-400 and 30-60 $\mu \mathrm{M}$, respectively [130]).

Third, many compounds are synthesised by CPs or leptomeninges in health or response to disease or trauma, and secreted into CSF for CNS use, for example, transthyretin, IGF-II and NGF [15, 25, 26, 169].

The extent to which molecules exchange between CSF and ISF depends on many factors, including their chemistry (mass and lipophilicity), the presence and direction of concentration gradients, and the presence of cellular receptors or uptake mechanisms on tanycytes, astrocytes, and neurons. However, it is clear that such exchange is an important part of CNS function and homeostasis.

\section{Blood vessels and the perivascular space}

Arteries in the subarachnoid space penetrate into the brain parenchyma, carrying with them a number of layers (Fig. 1). The arteries branch into arterioles and then capillaries, followed by transition into venules and veins and finally vascular return to the brain surface. At the capillary level, transverse sections show one or more endothelial cells lining the lumen and a number of associated cell types including pericytes and astrocyte foot processes (endfeet), together with their basal laminae, forming the neurovascular unit (NVU).

The perivascular spaces $(\mathrm{PVS})^{1}$ of cerebral blood vessels have in recent years been the subject of increasing research focus as pathways for CSF/ISF exchange [1, 74, 89, 91, 95, $112,137,138,162]$, but controversy exists over their precise role $[58,77,96,161,162]$. Indeed, the glial components (astrocyte foot processes) that provide the outer boundary

\footnotetext{
${ }^{1}$ Definitions: 'Peri' is enclosing or surrounding (as in pericardial, perimeter); 'Para' has many, less specific meanings, along or beside, e.g. parathyroid - but this does not really apply to circumferential structures. In common terms, 'para' is alongside (as in paramedic) or relating to, not the structure enveloping something closely. So here we have chosen to use the term 'perivascular' for the small spaces surrounding vessels in which tracer can move, and this is also its most common usage for the $\mathrm{BBB} / \mathrm{NVU}$.
}

of the PVS within the parenchyma have been proposed to serve a special function for CNS clearance and waste turnover, forming the basis for a so-called 'glymphatic' circulation $[91,124]$ that may potentially allow a more complete exchange of CSF and ISF at both superficial and deep sites spanning the entire neural axis. Such a PVS (Fig. 1a) may be identified on all larger cerebral blood vessels in both the subarachnoid spaces (leptomeningeal blood vessels) and within the parenchyma. Filled with a fluid in potential communication with both CSF and ISF but also containing connective tissue, scattered cells, and basement membranes (BM), the PVS is a real compartment within the vascular connective tissue space of the adventitia $[63,97,108,137,158,194$, $200]$ and possibly also the tunica media BM of large vessels $[24,137,189]$ as well as a potential compartment within the basal lamina of capillaries [74, 91, 137, 148]. Potential routes of entry from the CSF into the PVS include specialized pores, termed stomata, recently demonstrated on the adventitial lining cells of leptomeningeal vessels in the SAS of the rat by scanning electron microscopy [137] (Fig. 1b), confirming earlier decades-old identification of such structures in cats [199]; similar pores may also exist on the pia $[30,146]$, providing an additional route into the PVS via the subpial space (discussed in [137]). It has become increasingly clear that substances within the CSF may potentially access and distribute along the PVS to varying extents all throughout the cerebrovascular tree, e.g., large full length antibodies (immunoglobulin $\mathrm{G}$ ) have been shown to access the PVS of arterioles (Fig. 1c), capillaries (Fig. 1d), and venules following intrathecal infusion in rats [137]. The demonstration that CSF-infused tracers can distribute perivascularly even along microvessels comprising the classical NVU has now led to a number of interesting questions regarding (1) how such a perivascular distribution might accomplish CSF-ISF exchange, (2) the roles that astrocytes may play in regulating CSF-ISF exchange, and (3) the transport processes (e.g., diffusion, dispersion, or convection) governing fluid and tracer movement within the PVS and the surrounding brain ECS (Fig. 2). The PVS is unquestionably a site of great importance due to its involvement in disease processes affecting the NVU (e.g., cerebral amyloid angiopathy, present in $>90 \%$ of Alzheimer's disease brains and a major cause of intracerebral haemorrhage in the elderly; [70, 87, 176]), emerging roles in physiology (e.g., immune surveillance, central waste clearance and the proposed 'glymphatic' concepts; [95, 121, 124, 137]), and as a critical gatekeeper for widespread central drug delivery [137]. 

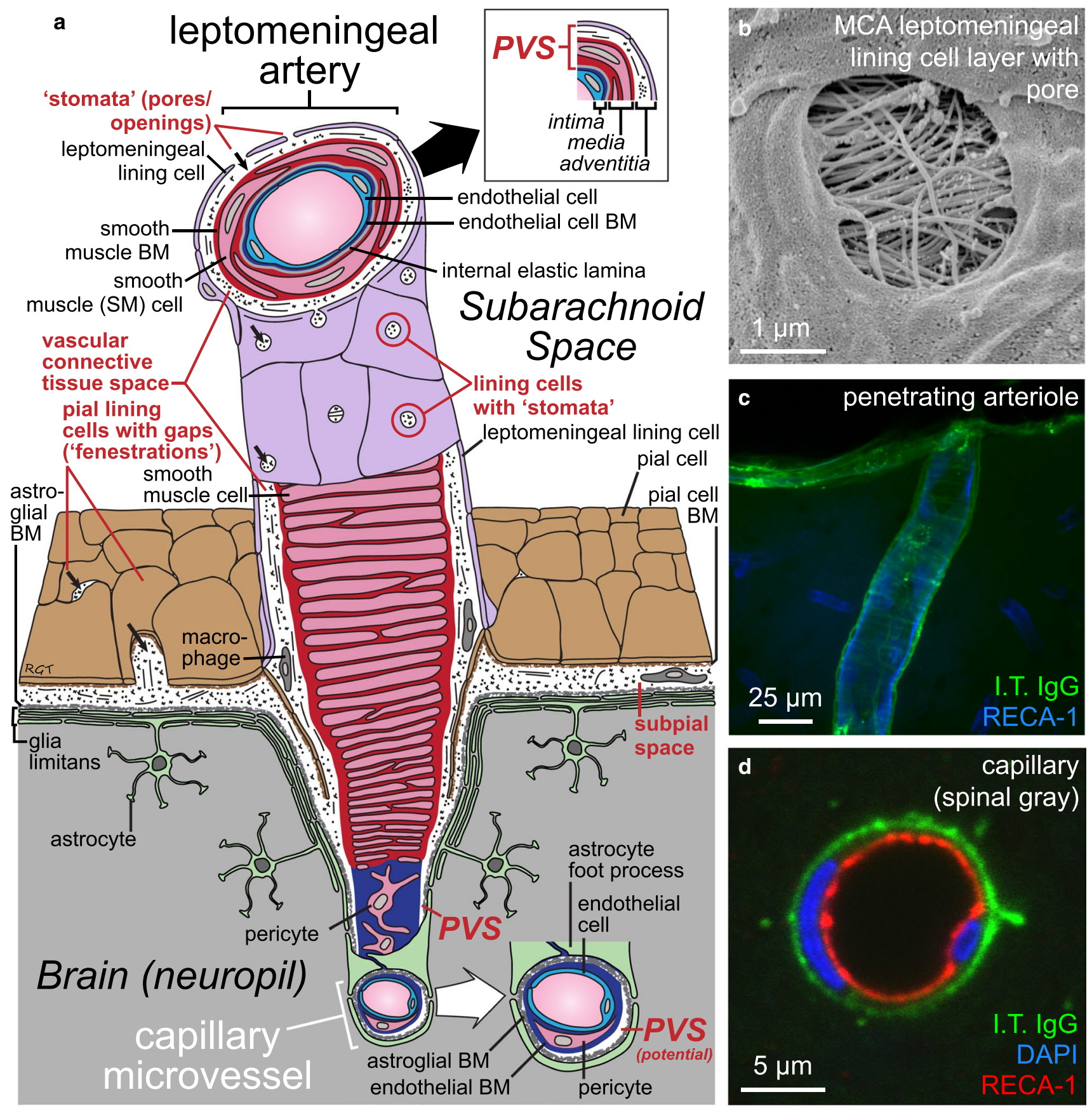

Fig. 1 Perivascular space (PVS). a Schematic depicting a leptomeningeal artery in the subarachnoid space as it penetrates into the brain parenchyma (neuropil), with a gradually thinning smooth muscle cell layer (tunica media) and narrowing lumen diameter. Smooth muscle cells become sparser as vessel size decreases, with capillary microvessels characterized by a small lumen, pericytes, and a basal lamina originating mainly from capillary endothelial cells and astrocytes. Key locations of potential CSF and ISF exchange are labelled with red text: (1) stomata/pores present on the CSF-facing leptomeningeal lining cells that have been identified on the outer surfaces of arteries in the subarachnoid space; (2) fenestrations/gaps/clefts on the CSF-facing pial lining cells of the brain surface; and (3) the PVS, a fluid compartment within the outer walls of blood vessels that includes the vascular connective tissue space of the arterial/arteriolar adventitia, the basement membrane (BM) surrounding smooth muscle cells in the tunica media, and potentially extends all the way down to a pericapillary fluid space between astroglial and endothelial BM of microvessels. Veins/venules are not depicted. b Scanning electron micrographs show the existence of numerous pores/openings termed 'stomata' on the outer leptomeningeal sheaths of blood vessels in the subarachnoid space. Shown: middle cerebral artery (MCA) leptomeningeal surface (rat) exhibiting a micron-sized pore with noticeably dense, underlying perivascular fibres in the vascular connective tissue space (see [137]). c-d Fluorescently labelled non-targeted immunoglobulin $\mathrm{G}(\mathrm{IgG})$ antibodies intrathecally (I.T.) infused at a low flow rate $(80 \mu \mathrm{l}$ applied cisternally over $50 \mathrm{~min})$ reveal prominent perivascular signal along all vessel types in the rat, including cortical penetrating arterioles and numerous microvessels (shown). RECA-1, rat endothelial cell antigen-1 (endothelial cell marker) (d adapted from [137]) 


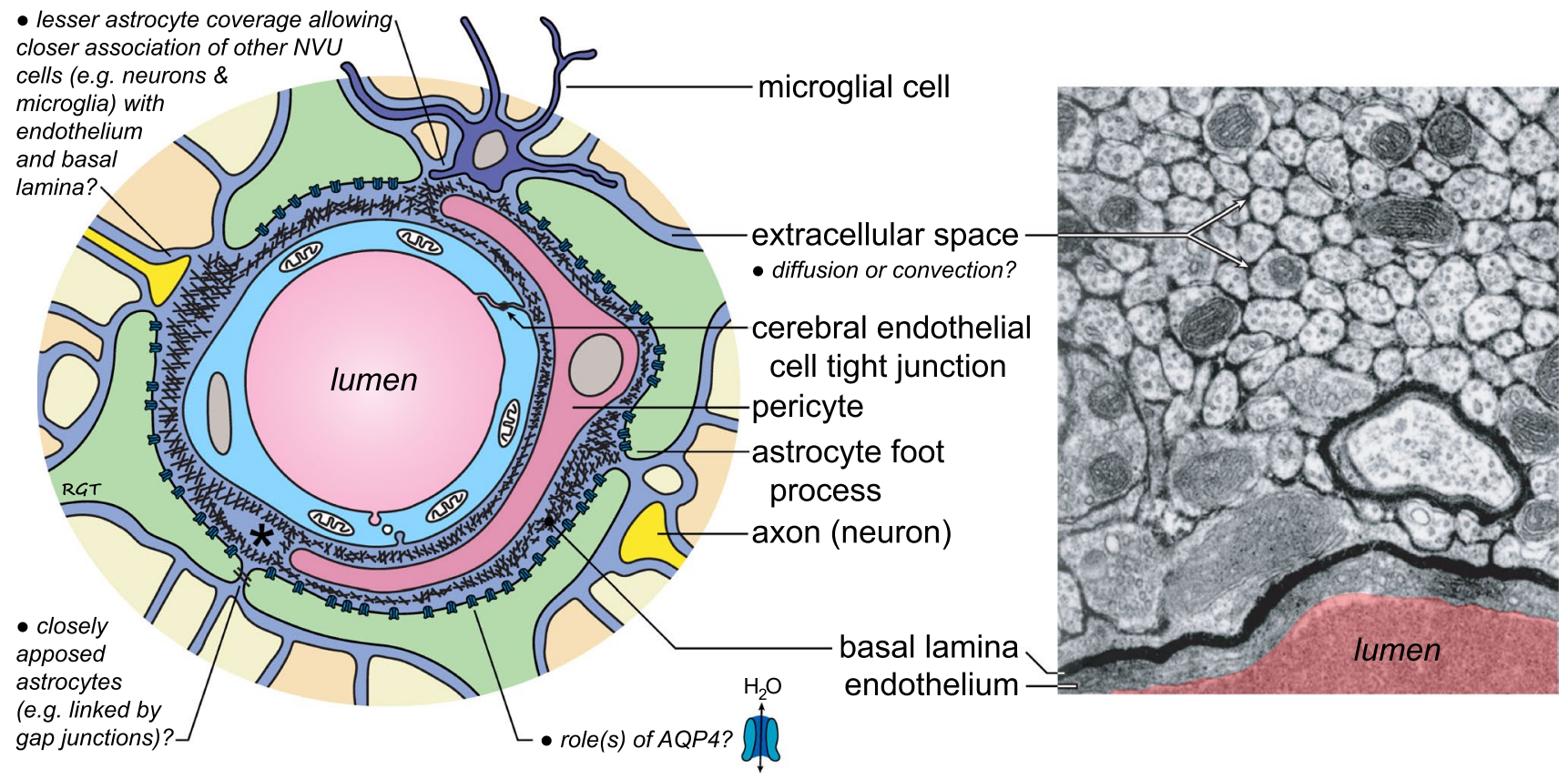

Fig. 2 Neurovascular unit (NVU). The NVU refers to the monolayer of brain endothelial cells making up CNS blood vessels (and smooth muscle cells for larger caliber vessels), their associated neurons, and the numerous non-neuronal cells (e.g., pericytes, astrocytes, and microglia), extracellular matrix and basement membranes that surround them; our understanding of the NVU and the details of the extensive coupling, association, and regulation that exists between NVU components remains a highly active area of investigation. Key questions (bulleted text) include the degree of astrocyte coverage (e.g., are adjacent astrocyte foot processes nearly always closely situated or do larger gaps exist to allow more intimate association of

\section{Historical considerations: CSF/ISF exchange and flow along low-resistance pathways including the PVS}

It was recognized over one century ago that CSF was primarily formed by the choroid plexuses in the ventricles of the brain, through which it flowed before reaching the cranial and spinal SAS $[38,186]$. Even then, it was thought that ISF secreted at the BBB may drain along perivascular spaces out of the brain and into the CSF to clear the brain of waste $[38,186]$, a concept revisited 60 years later by Helen Cserr to explain how the brain, lacking the classical lymphatics of the periphery, might accomplish efficient waste removal [32, 36, 37]. Importantly, Cserr and colleagues [32-36] revived an earlier idea that a convective or bulk flow of ISF occurred along specialized pathways in the brain to communicate with and drain to the CSF. The key experiments involved the injection of small volumes $(<1 \mu \mathrm{l})$ of $2000 \mathrm{kDa}$ blue dextran [36] or $40 \mathrm{kDa}$ horseradish peroxidase [33] into the caudate nucleus. Although tracer profiles close to the injection site were interpreted as suggestive of short range diffusive transport in brain ECS, longer range transport seemingly neurons, microglia and other cells with the endothelial cell and its associated extracellular matrix?), the roles subserved by aquaporin-4 (AQP4) water channels highly expressed on astrocytic endfeet, the normal mode of fluid/tracer transport in the extracellular space, and whether a pericapillary fluid space normally exists in the basal lamina (indicated with an asterisk), see text for discussion. The transmission electron micrograph (right) illustrates the extensive distribution of $40 \mathrm{kDa}$ horseradish peroxidase through the extracellular space and the basal lamina of a cerebral blood vessel following intraventricular administration (adapted from [20] with permission)

inconsistent with diffusion was also observed along the perivascular spaces of blood vessels, along white matter tracts, and within the subependymal region and interpreted as having been produced by convective transport (bulk flow).

Subsequent studies showed that a variety of different radiolabelled tracers were cleared from the brain with similar rate constants, despite vast differences in molecular size and diffusion coefficient, again suggestive of a clearance process that was convective in nature $[33,34]$. While others disagreed with the existence of these convective flow pathways for ISF-CSF exchange, arguing that diffusion through the brain ECS was solely responsible for drainage [43, 133], a general consensus emerged around the idea that ISF is largely produced by secretion of fluid across the capillaries $[1,33]$, albeit with some contribution from the CSF [1], and that ISF is an important extra-choroidal source of CSF [119, 139]. Later studies complementary to Cserr's original work also suggested preferential routes for ISF flow in the white matter [150], particularly in the presence of brain oedema [99, 131, 132], and in the perivascular spaces [148].

Experiments and discussion suggesting that CSF could potentially flow into the brain along the perivascular spaces 
began in the early 1900s with several groups making contributions (discussed in: [94, 193]). Studies conducted by Weed (1914) [186] implied that increased intracranial/infusion pressure was required to achieve perivascular distribution of CSF-administered tracer, but subsequent work by Brierley (1950) [18] demonstrated perivascular distribution was possible with a physiological/minimal pressure increase. Later notable insights were provided by (1) Wagner (1974) [185] and Rennels (1985) [148], who showed that CSFinfused substances may be capable of reaching the PVS of capillaries, (2) Rosenberg [150] and Konsman [104], who demonstrated the involvement of the white matter as a bulk flow pathway for CSF-infused substances, (3) Fenstermacher and Patlak (1970, 1975) [111, 135], Rosenberg (1980) [150], Ghersi-Egea (1996) [68], and Proescholdt (2000) [142], who performed experiments where the penetration of CSFinfused tracers across the brain-CSF interfaces appeared consistent with diffusive transport, and (4) Krisch (1983, 1984) [107, 108] and Ichimura (1991) [88], who demonstrated communication between the ECS, PVS, subpial space, and subarachnoid trabeculae core following CSF infusion of tracer. It must be noted that the group of Weller and Carare have interpreted a number of their own more recent studies injecting tracers into the brain parenchyma as suggesting outward directed flow of ISF/solutes primarily confined to the capillary basal lamina and the smooth muscle basement membrane (tunica media) of arterioles/ arteries [24, 120], a process they have termed an 'intramural peri-arterial drainage' pathway $[48,58]$. Nevertheless, most experimental work and modelling to date has been interpreted as supporting some type of inward transport process from the CSF to the brain within the vascular connective tissue space of the tunica adventitia of arteries and arterioles (see $[1,77,137]$ for more discussion).

The 1985 publication of Rennels et al. with CSF infusions of HRP stands out for both the speed at which the tracer distributed throughout the brain (taking as little as $10 \mathrm{~min}$ ) and for the bold suggestion that a rapid 'paravascular' fluid circulation of CSF must exist along perivascular spaces comprising the entire vascular network (i.e., arteries $\rightarrow$ capillaries $\rightarrow$ veins) to account for it [148]. While certain aspects of the Rennels work were questioned in the decade after their publication [88], the past 5 years have witnessed a dramatically renewed interest in a possible circulation of CSF and CSF-borne tracers along perivascular spaces with relevance for CSF-ISF exchange, initially stimulated by new work from Nedergaard and colleagues [91].

\section{The 'glymphatic' system: original hypothesis and critical appraisal}

In 2012, Iliff et al. reported findings based on intracisternal injections of fluorescently labelled dextrans and ovalbumin in mice, real-time monitoring of tracer movement using in vivo two-photon microscopy via a closed cranial window preparation, and ex vivo confocal microscopy that suggested to them a brain-wide system of 'paravascular pathways' [91]. Live animal two-photon imaging was used to show that fluorescence from infused tracers first appeared along the PVS of arteries on the brain surface and their associated penetrating arterioles and only later along capillaries and draining venules. They observed that both a small $(3 \mathrm{kDa})$ and very large $(2000 \mathrm{kDa})$ dextran each appeared to be rapidly transported over great distances via the PVS (suggesting convective flow); however, only the smaller dextran appeared to efficiently leave the PVS to access the brain interstitium, interpreted as the result of 'sieving' by presumed narrow $(\sim 20 \mathrm{~nm})$ gaps between astrocyte endfeet. When the same experiments were repeated in aquaporin-4 (AQP4) null mice, Iliff et al. reported that intracisternal ovalbumin (45 kDa) entry into the brain parenchyma was significantly diminished $30 \mathrm{~min}$ following a $5 \mathrm{~min}$ infusion $(2 \mu \mathrm{l} / \mathrm{min})$; furthermore, in vivo two-photon imaging showed that while $2000 \mathrm{kDa}$ dextran access to penetrating arteriole PVS did not appear to be significantly altered in AQP4-null animals, penetration of $3 \mathrm{kDa}$ dextran into the surrounding interstitium was dramatically reduced. Clearance of radiolabelled tracer substances out of the brain also tended to be reduced $1-2 \mathrm{~h}$ after intrastriatal injection in AQP4-null animals.

Taking account of these results together with speculated roles for how perivascular AQP4 might be affecting tracer distribution, as these water channels are enriched on glial (astrocyte) endfeet [9, 128], Iliff et al. hypothesized three serial steps of a glial-lymphatic or 'glymphatic' system for waste clearance: (1) initial convective flow of subarachnoid CSF into the brain along peri-arterial spaces; (2) AQP4facilitated water and tracer flow from this peri-arterial space through the brain ECS ('transparenchymal' convection) resulting in directed transport of ISF toward venules/veins; and (3) clearance out of the brain along peri-venous spaces $[90,91,124,125]$.

A major critique of the 'glymphatic' hypothesis involves the proposed role of AQP4. Aquaporins are a large family of cell membrane channels containing $\sim 0.5 \mathrm{~nm}$ pores [72] that confer selective permeability to water and, in some cases, certain other small molecules; AQP1, AQP4, AQP5, and AQP9 are present in rodent brain [9]. AQP4 is particularly enriched in the brain at CSF interfaces [98], with polarized expression in astrocytes at the pial surface-facing glia limitans, in ventricle-facing ependymal cells, and, importantly, 
within perivascular endfeet that form the boundary between the parenchymal blood vessels and the neuropil [128] (Fig. 2). It has been unclear by what precise mechanism(s) perivascular astrocytic AQP4 water channels might facilitate a transparenchymal flow of ISF and perivascular macromolecule tracers under normal conditions, as proposed in the 'glymphatic' concept, particularly because (1) directed convection from the arterial PVS to the venule PVS through the neuropil interstitium would depend on a hydrostatic pressure/osmotic gradient that is difficult to envision [161], (2) AQP4 is incapable of transporting macromolecules, and (3) much experimental work has suggested the high hydraulic resistance of the brain ECS would greatly restrict such a flow in favour of diffusion [80, 138, 192]. In addition, a transparenchymal flow of ISF, solutes, and waste would appear difficult to reconcile with the required homeostasis of the brain microenvironment for synaptic transmission. Aquaporins clearly do play diverse roles in brain water balance in health and disease $[9,84]$ and such concepts have undoubtedly informed the 'glymphatic' hypothesis. The previous studies performed on AQP4-deficient mice have demonstrated that such animals exhibit an increased brain ECS volume fraction [196], increased basal brain water content [73], and larger intracranial pressure elevations in response to induced vasogenic (non-cellular) oedema [134], suggesting that AQP4 indeed plays critical roles in the transport of water between brain compartments as well as the formation and resolution of oedema. The key question for the 'glymphatic' concept is just what role astrocytic AQP4 may play in the circulation of fluid in perivascular compartments and how its deletion affects such circulation.

Verkman and colleagues have further argued that the proposed 'glymphatic' hypothesis and its reliance on AQP4 are implausible based on physiological grounds [161] and recently reported on their own experimental work testing key aspects of the original Iliff et al. studies [162]. Interestingly, this new work [162] emphasized that tracer movement in the brain parenchyma (outside of the perivascular spaces) was size dependent and consistent with diffusion as the mechanism of transport, using a cisternal infusion paradigm in mice that was very similar to that employed by Iliff et al. [91]. A separate recent experimental study in rats [137] has also confirmed the role of tracer size-dependent diffusive transport at the pial brain surface using a similar cisternal infusion paradigm to the Nedergaard group [89]. Finally and perhaps most importantly, the Verkman group replicated many of the original Iliff et al. cisternal infusion experiments in AQP4-null animals and found no qualitative or quantitative differences in ovalbumin distribution between wild type and AQP4 null mice (or between wild type and AQP4 null rats) [162]. Further work will be required to resolve the precise role(s) that AQP4 water channels may or may not play with respect to tracer distribution in the perivascular and parenchymal compartments.

The role of brain capillaries in secreting a fluid suitable for the optimal function of neurons and glia was largely ignored in the early conception of the 'glymphatic' system. The evidence for origin of ISF as a secretion across the brain capillary endothelium is well established; in vivo studies show good regulation of brain ions in the face of large changes in plasma concentration, and the necessary ion channels and transporters are expressed at the BBB [1, 151]. Careful studies in primary cultured brain endothelial cells have provided a complex map of ion transporters and channels on apical and basal membranes, and the ways in which they could generate the required fluid flow [78]. As the flow rate per unit area is low compared with choroid plexus secretion of CSF, it is not possible to demonstrate fluid production from segments of isolated brain capillary, but the net result is to supply local regions of the neuropil with fresh fluid of optimal composition for neural function. Interestingly, the brain endothelium shows down-regulation of the AQP1 highly expressed on non-brain endothelial cells [51], consistent with the need to limit the rate of fluid production to maximize local ionic homeostasis. If a large percentage of the ISF were provided from recirculated CSF as might be implied by the 'glymphatic' hypothesis, this would contain waste products from all the upstream sites exposed to that CSF, a much less suitable medium for optimal neural function.

\section{Diffusion or flow of the ISF in the brain ECS?}

A great many studies using a wide variety of tracer substances and multiple different ex vivo/in vivo methods have concluded that the local transport of small and large molecules through the brain ECS of the neuropil is predominantly diffusive in nature; such studies have included ventriculo-cisternal or subarachnoid-cisternal perfusion of radiolabelled tracers [111, 135, 144], real-time iontophoresis of the small tetramethylammonium ion [126], and integrative optical imaging (IOI) of pressure-injected fluorescently labelled molecules [127, 178-180, 191]. Electron microscopy studies focused on neuropil ultrastructure have long indicated a brain ECS width of approximately $10-20 \mathrm{~nm}[21$, $75,81,136]$ and, importantly, that these narrow spaces could be accessed with tracers such as HRP (40 kDa) following intracerebroventricular injection [20,21].

More recently, Thorne and Nicholson used in vivo diffusion measurements to demonstrate that the ECS width in rat somatosensory cortex is substantially wider in living animals than these earlier EM-based estimates from processed, conventionally fixed tissue had indicated [180]. Integrative optical imaging (IOI) of intraparenchymally injected 
dextrans and quantum dots ranging from 3 to $35 \mathrm{~nm}$ in size showed that (1) transport in the neuropil of living animals could be adequately described by diffusion theory and (2) modelling the brain ECS as cylindrical pores or as parallel planes and fitting such models (with the application of hydrodynamic theory for hindered diffusion) to experimental data led to ECS width estimates of approximately 40-60 nm [180]. Subsequent in silico modelling work based on expansion of actual tissue geometry from serial EM to match the established physiological brain ECS volume (20\%; [171]) has mostly agreed well with the earlier IOI diffusion measurement-based estimates of brain ECS width [102]. It has long been suggested that the reason diffusive transport is strongly favoured over flow in the brain ECS under most conditions is that the hydraulic resistance of such narrow spaces is too high for bulk flow to occur even in the presence of a significant pressure difference [60, 80, 192]. Recent modelling studies of tracer movement through the ECS have continued to suggest that flow in the ECS (as suggested by the 'glymphatic' hypothesis) is unlikely $[80,96]$.

There is currently much discussion regarding how the brain ECS as well as tracer transport from CSF into the brain may be affected by different brain states, i.e., awake versus sleeping versus anaesthetized conditions. Significant transport of a variety of different tracers into the brain from the CSF has now been demonstrated in vivo in rodents subjected to a wide variety of anaesthetics, including ketamine/xylazine [92, 195], isoflurane [89], avertin [162], and urethane [137]. It has been suggested by Nedergaard and colleagues that the influx of tracers such as $3 \mathrm{kDa}$ dextran from the CSF to the brain is profoundly suppressed in awake mice compared to naturally sleeping or ketamine/xylazine anaesthetized mice [195]; reduced brain influx and circulation of CSF-infused tracer was further suggested to be the result of a significantly reduced brain ECS volume (and changes in ISF ionic composition [50]) associated with the awake state [195], a novel finding in itself that needs to be studied further and subjected to replication. Although interesting, decreased transport of substances from the CSF to the brain and a decreased brain ECS in awake animals have subsequently been challenged both conceptually [77] and experimentally [65]. Indeed, Gakuba and colleagues recently used MRI and other methods to show that isoflurane-, ketamine/ xylazine-, and ketamine-anaesthetized mice actually exhibited reduced CSF-to-brain influx of intrathecally infused contrast agent (DOTA-Gd), Evans blue, and 775 Da indocyanine green dye as compared to the awake state [65]. More work will be needed to resolve the discrepancies between different groups and the effects that different methods and tracer substances may have on the findings.

\section{A sieving effect of perivascular astrocyte endfeet?}

It is tempting to speculate that transport from the perivascular space into the adjacent brain ECS may be restricted or regulated based on the size of the gaps between adjacent astrocyte endfeet bordering the perivascular space; indeed, Iliff et al. concluded that these gaps were likely responsible in some way for the sieving effect that they observed between the distributions of small and large cisternally infused dextrans (discussed above; [91]). Transmission EM measurements from conventionally prepared, aldehyde-fixed tissue have suggested that such endfoot-endfoot clefts are approximately $20 \mathrm{~nm}$ wide (similar to the conventional EM-based estimates of ECS width) [114]. However, a more recent transmission EM study using cryofixation methods suggested that astrocyte coverage of cerebral blood vessels was significantly less complete than previously shown [105], calling into question whether astrocyte endfoot sieving indeed occurs. The Korogod et al. figure for ECS volume in the relatively uniform brain parenchyma $(\sim 15 \%$ with cryopreservation cf $\sim 2.5 \%$ with the conventional fixation) is encouragingly closer to physiological measurements, so that in this case, cryopreservation may well give a truer picture of the ECS than the conventional fixation. However, it is harder to assess the data for perivascular coverage by astrocytes ( $62 \%$ cf $>90 \%$ with the conventional fixation).

Figure 3 provides a summary of the major junctions and adhesions that have been described for endothelial cells and astrocytes at the BBB [3, 11, 62, 86, 117, 168, 182, 201]. Endothelial cell-astrocyte interactions occur in part through complex associations with the extracellular matrix (ECM) and basal lamina that are mediated by integrins, $\alpha \beta$ heterodimeric receptors that bind extracellularly to laminins and fibronectin to link the ECM to the cytoskeleton, and dystroglycan, a complex of $\alpha$ and $\beta$ subunits that binds to laminins, agrin, and perlecan to provide additional links of the ECM to the cytoskeleton. Many additional linkages between laminins, proteoglycans, fibronectin, type IV collagen, and other ECM/basal lamina constituents have also been described [11, 117, 201]. In life, there is evidence that the astrocyte endfeet are strongly linked to the basal side of the endothelial cells by numerous such integrin-dystroglycan complexes, involving integrins in the endothelial basal cell membrane interacting with extracellular laminin and fibronectin, connecting collagen IV and proteoglycans in the extracellular space to dystroglycan inserted in the underlying astrocyte end feet membrane. Similarly, it is proposed that the astrocytic layer forms an effective 'second barrier' surrounding the endothelial tube, with connexin 43 gap junctions linking adjacent astrocyte endfeet [64], and the 


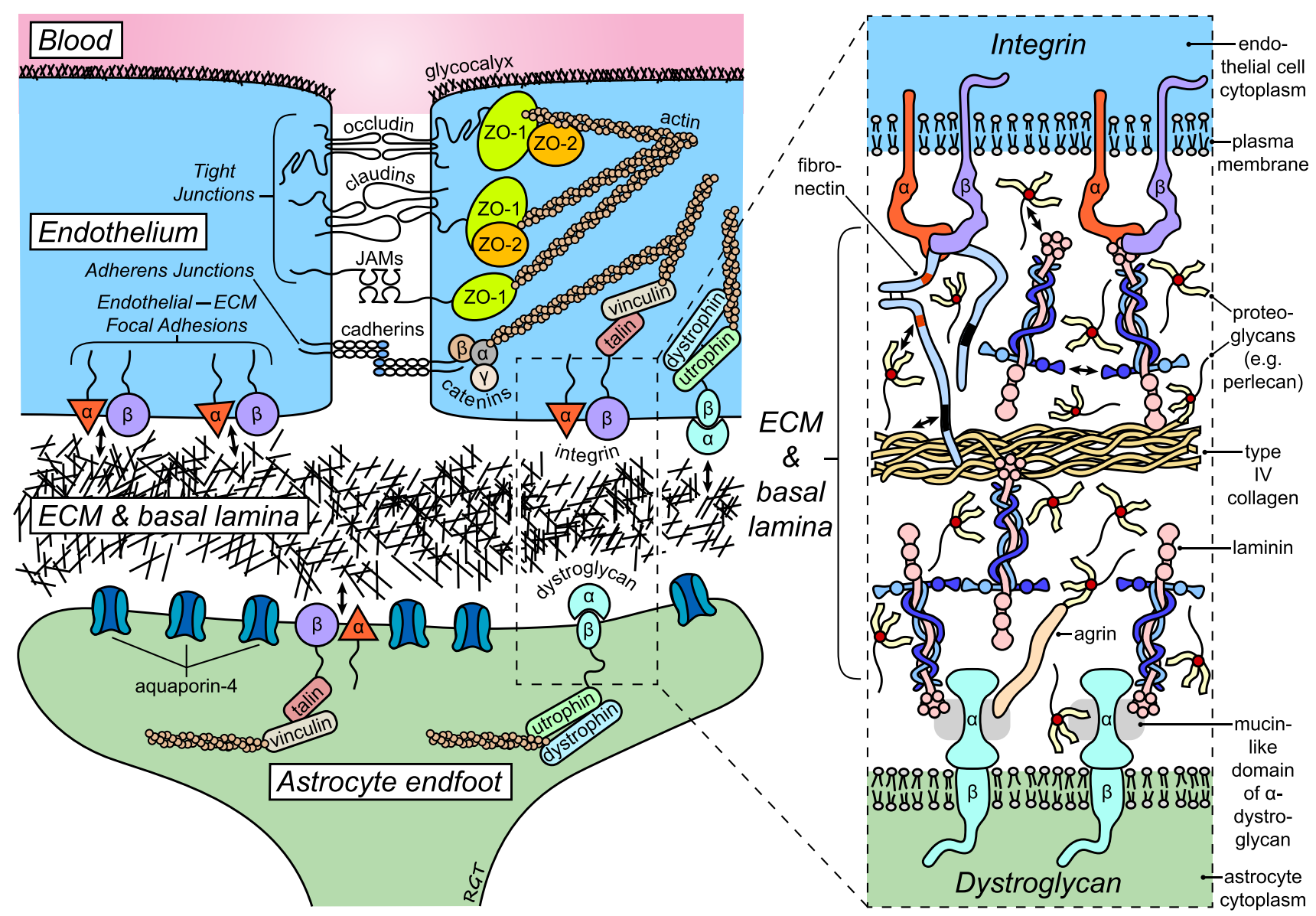

Fig. 3 Junctions and adhesions of the blood-brain barrier (BBB) and cerebral microvessel basal lamina. Several different tight junction proteins restrict and regulate paracellular diffusion as well as the diffusion of membrane components between the luminal and abluminal compartments of polarized endothelial cells; these include occludin, claudins-3, -5 , and -12, zonula occludens-1 (ZO-1) and -2 (ZO2 ), and various junctional adhesion molecules (JAMs), all of which also participate in complex linkages with the actin cytoskeleton that allow endothelial cells to sense and respond to internal and external forces. Adherens junctions consisting of vascular endothelial cadherins and associated intracellular scaffold proteins such as the catenins regulate cell-cell contacts and tensile forces through additional link- ages with the actin cytoskeleton. Interactions of endothelial cells (and astrocytes) with components of the extracellular matrix (ECM) and basal lamina are facilitated by integrins, $\alpha \beta$ heterodimeric receptors that bind extracellularly to laminins and fibronectin to link the ECM to the cytoskeleton, and dystroglycan, a complex of $\alpha$ and $\beta$ subunits that binds to laminins, agrin, and perlecan to provide additional links of the ECM to the cytoskeleton. Numerous additional linkages within the ECM and basal lamina occur between laminins, proteoglycans, fibronectin, and type IV collagen (arrows), among others (Adapted from $[11,86,168,201]$ with additional information incorporated from $[3,62,117,182])$

condition, it is possible that the organization of adjacent perivascular astrocyte foot processes is captured more effectively in aldehyde-preserved tissue than in the TEM images captured after cryopreservation, where ice crystals may disrupt the fragile cell:cell associations in the neurovascular unit and perivascular space. More research is needed to resolve this question. The conclusion is that it is important to bear in mind the physiology when interpreting microscopic images, especially those potentially subject to fixation/freezing artefacts.

It bears stressing that basement membranes may prove to play a critical role in the sieving of perivascularly located molecules attempting to enter the brain 
parenchyma [19, 20, 74]; indeed, recent experimental work has demonstrated that intracisternally infused small single-domain antibodies (17 kDa; $4.5 \mathrm{~nm}$ apparent hydrodynamic diameter) more fully access perivascular basement membranes than similarly infused large full length immunoglobulin $\mathrm{G}$ antibodies (150 kDa; $10 \mathrm{~nm})$ [137]. A recent molecular characterization of the PVS with respect to laminin composition and other markers by Sorokin and colleagues provides new, critical information for future work in this area [74].

\section{ISF bulk flow}

Confusion has long been associated with what different groups have meant in suggesting or describing "ISF bulk flow". The pioneering work of Helen Cserr and a number of her contemporaries often made mention of "bulk flow of ISF", but careful reading reveals that this typically was intended to describe flow principally limited to lowresistance pathways such as the perivascular spaces and white matter tracts $[1,33,150]$ and not within the narrow and tortuous brain ECS. In summary, it seems increasingly likely that a great many studied macromolecule tracers as well as endogenous proteins in the CSF distribute into brain tissue via transport processes that may be adequately described by some combination of diffusion in the ECS and convection in the perivascular spaces $[68,137,142$, $148,185]$.

\section{CSF and ISF compartmentalization and drainage pathways}

CSF and ISF are generally considered to be similar in composition [1, 37, 77, 177], with the exception that the ISF exists in an environment containing an abundant ECM that may play key roles in CSF/ISF transport and exchange [171, 177]. The polyanionic nature and binding capacity of the ECM may significantly impact the diffusion of certain ions and other molecules in the brain ECS (e.g., confinement or binding of ions by perineuronal nets [76] or chondroitin sulphate proteoglycans [83], sequestration of growth factors [173], and protein binding to heparan sulphate proteoglycans [179]). CSF-ISF exchange of molecules is, therefore, expected to be limited by (1) molecular size, (2) ECM interactions, (3) receptor binding, (4) aggregation state (e.g., certain pathogenic proteins), (5) permeability characteristics (e.g., clearance across the BBB), and (6) distance from the brain-CSF interface, and likely other factors.

The precise drainage pathways for CSF and ISF out of the central compartment have also been the source of much recent interest. CSF drainage occurs directly into the blood via arachnoid villi or granulations into the venous sinuses of the dura mater and also into the lymphatic system via cranial and spinal nerves [138]. Drainage occurs along the olfactory nerves to the nasal mucosa to the cervical lymph nodes [16, 17, 59, 101, 172, 188] and along spinal nerves to cervical, intercostal, and other lymph nodes [103]. An additional pathway for CSF/ISF drainage appears to occur within dural lymphatic vessels to the cervical lymph nodes [7, 113], but just how CSF enters the dural lymphatic vessels has not been well described.

Tracer studies suggest that the drainage of ISF and CSF from the brain is compartmentalized. For example, the transport and drainage of ISF-administered tracers have shown significant lateralization; brain-injected tracers appear to preferentially drain along perivascular spaces on the same side as the injection and into ipsilateral cervical lymph nodes [16, 172]. By contrast, CSF-administered tracers drain into cervical lymph nodes on both sides [101, 137, 172]. Studies of nose-to-brain transport further support some degree of separation between CSF and ISF [181]. Földi and colleagues have long proposed that drainage of ISF along the PVS is indeed compartmentalized from the CSF as it drains from the brain, possibly by the presence of the cells ensheathing the vessel in the subarachnoid space [61] (e.g., as described by [4]). In addition to tracer studies, antigenic responses also appear to suggest a compartmentation of CSF and ISF $[58,66]$, as parenchymal tissue grafts and ISF antigens elicit more limited immune responses (e.g., [122, 155, 167]) than CSF-administered tissue or antigen that usually results in a strong immune response (e.g., [122, 167]). In summary, a synthesis of the older descriptive work on ISF-CSF relationships and fluid turnover and clearance from the central compartment, together with more recent work incorporating more sophisticated molecular characterization of specific drainage pathways out of the CNS to venous blood and draining lymph nodes, suggests that there remain gaps in our understanding of the precise relationships, pathways, and their relative importance. Further work is clearly needed in this area.

\section{Practical and clinical implications of ISF/CSF interaction}

CSF sampling has inherent problems associated with studying the composition and dynamics of CSF which include: pharmacological effect of anaesthesia; confounding effects of circadian rhythm; inflammation during disease or surgical intervention; and changed ventricular pressure after removing CSF or adding tracers into the enclosed ventricular system. All these will affect CSF flow and/or production, 


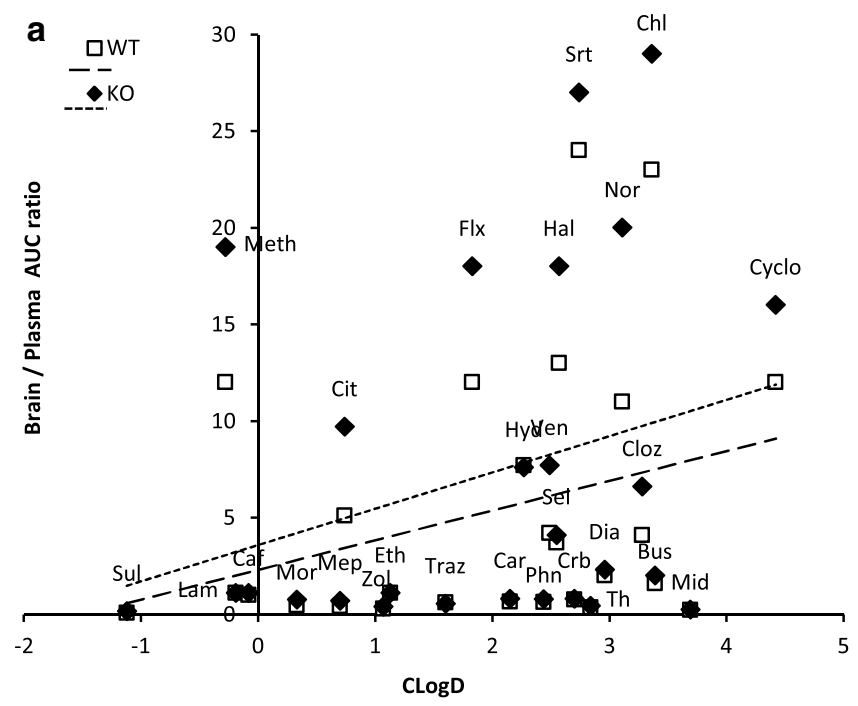

Fig. 4 Brain/plasma (a) and CSF/plasma (b) AUC ratios for CNSactive agents plotted against their CLogD values, in Female FVB (WT) and mdr1a $\mathrm{a}^{-l-} / 1 \mathrm{~b}^{-l-}(\mathrm{KO})$ mice. Re-analysis of data from Doran et al. [52]. Mice were administered with $3 \mathrm{mg} / \mathrm{kg}$ drug s.c. $(5 \mathrm{mg} /$ $\mathrm{kg}$ caffeine) then brain, CSF and plasma taken at $0.5,1,2.5$, or $5 \mathrm{~h}$ post-dose. Drug analysis was by HPLC/mass spectrometry, yielding the area under the curve (AUC). For this analysis, drugs with weak P-glycoprotein interaction (brain uptake KO: WT ratio $<2$ ) were selected from the original data set of 33 compounds, $n=5$ mice per genotype per timepoint. The inverse correlation between CSF/plasma ratio and drug lipid solubility CLogD (b) shows that the most lipidsoluble drugs had the smallest distribution in CSF in both WT and

potentially influencing data obtained (these and other confounding factors are discussed in detail elsewhere [166]). Sampling CSF multiple times is a particular problem when comparing healthy and diseased states, or young versus old. Removal of fluid and reduction in intracranial pressure alter CSF dynamics until the fluid can be replenished, and replacement rate is faster in the young or healthy $(591 \mathrm{ml} /$ day, human), compared to in older or pathological situations $(294 \mathrm{ml} /$ day $)[145,157]$. As a result, biomarkers or drugs are expected to be concentrated in the smaller volume of fluid of the old or with certain diseases. For example, Slats et al. [160] sampled $6 \mathrm{ml}$ of patients' CSF every hour for $36 \mathrm{~h}$ using indwelling L3-4 lumber puncture cannula. They noted total CSF protein and pathological tau increased over the study period in the Alzheimer's disease patients, but not in age-matched controls, suggesting an artefact in sampling from the frailer patients.

Another important issue is assessing CSF uptake of systemic drugs when plasma concentration is $10-100 \times$ greater than CSF or brain. Contamination of the CSF sample with whole blood or plasma must be ruled out, but microscopic inspection for erythrocytes cannot always rule out contamination because erythrocytes may lyse. Tests for haemoglobin

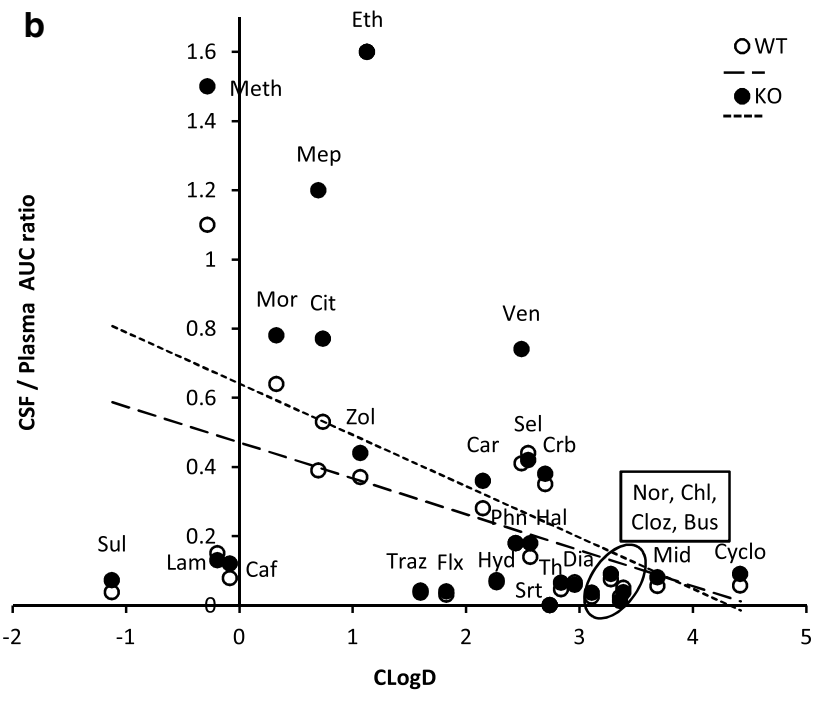

KO mice $(p<0.05)$. Lines represent linear regression analysis for (a) Brain/plasma; WT open squares, $R^{2} 0.01, p=0.109$; KO filled diamonds, $R^{2} 0.09, p=0.138$ (b) CSF/plasma; WT open circles, $R^{2}$ $0.158, p=0.040$. KO filled circles, $R^{2} 0.206, p=0.017(d f=26)$. Bus buspirone, Caf caffeine, Car carisoprodol, Chl chlorpromazine, Cit citalopram, Cloz clozapine, $\mathrm{Crb}$ carbamazepine, Cyclo cyclobenzaprine, Dia diazepam, Eth ethosuximide, Flx fluoxetine, Hal haloperidol, Hyd hydroxyzine, Lam lamotrigine, Mep meprobamate, Meth methylphenidate, Mid midazolam, Mor morphine, Nor nortriptyline, $P h n$ phenytoin, $S e l$ selegiline, Srt sertraline, Sul sulpiride, Th thiopental, Traz trazodone, Ven venlafaxin, Zol zolpidem

are preferred, because even a 1 in 100 contamination with blood could significantly affect drug determination [27].

Using CSF as a proxy for brain drug levels is commonly used in both clinical and pre-clinical studies. However, the pitfalls are numerous and include the issues already mentioned above, as well as the fact that drug distribution in CSF depends on the chemistry of the compound and its interaction with uptake and efflux transporters at CNS/blood interfaces.

Doran et al. [52] very helpfully studied a library of Pfizer's small molecule drugs $<450 \mathrm{Da}$, measuring both brain and CSF uptake in mice after systemic administration. Reanalysis of their data (Fig. 4) shows that brain penetration increases as drugs become more lipid soluble (increasing CLogD); conversely, however, CSF penetration decreases as drugs become more lipid soluble. This is consistent with the aqueous CSF being less amenable to partitioning of lipidsoluble drugs compared to brain, where drugs are exposed to lipid cell membranes into which they can partition.

For hydrophilic drugs with CLogD $<1, \mathrm{CSF}$ drug content may be predictive of brain levels, because there is similar, modest distribution into both compartments and there is significant correlation between the two $\left(p=0.023, R^{2}=0.68\right.$, $d f=6$ ). However, for highly brain penetrant lipophilic drugs 
with CLogD $>3$, CSF uptake does not correlate with brain $\left(p=0.148, R^{2}=0.45, d f=5\right)$ and brain levels are on average $9 \times$ those in CSF.

Drug interaction with efflux transporters may also play a role. In mice lacking P-glycoprotein (mdr1 $\mathrm{a}^{-/-} / 1 \mathrm{~b}^{-/-}$knockout mice), there is even greater difference between brain and CSF distribution. This is mainly due to increased brain distribution in mdr $1 \mathrm{a}^{-/-} / 1 \mathrm{~b}^{-/-}$mice, since P-glycoprotein is not available to efflux the drug back to blood. For example, lipophilic drugs with CLogD $>3$ have brain levels on average $12 \times$ higher than CSF (compared to $9 \times$ CSF levels in wild-type mice). Even hydrophilic drugs' brain distribution is affected, increasing from $2 \times$ CSF levels in the wildtype mice, to $3 \times$ CSF levels in the $\operatorname{mdr} 1 a^{-/-} / 1 b^{-/-}$mice for drugs with $\mathrm{CLogD}<1$. In general, brain and CSF uptake of P-glycoprotein substrates are closer to each other at any given CLogD in the wild-type mice.

Therefore, it cannot be assumed that the presence of any compound in CSF is a true reflection of its brain level, particularly for lipophilic drugs that evade efflux transport. Similar data are not available for large molecules or biologics and would presumably be different for drugs interacting strongly with other transport or efflux systems.

\section{CNS pathologies and disturbances of brain fluids}

Several pathologies of the cerebral microvasculature, including the associated cells of the neurovascular unit, and the perivascular space, have been mentioned briefly above. Here, we focus on some additional brain pathologies with particular relevance to fluid drainage pathways and brainfluid flow.

Brain oedema is the accumulation of excess fluid in the brain, either in the intracellular (cytotoxic oedema) or extracellular compartments (vasogenic oedema) [123], though these two types of fluid accumulation rarely occur independently (e.g., certain pathologies including diabetes, stroke, and traumatic brain injury may involve both vasogenic and cytotoxic oedema $[55,175]$ ). Cytotoxic (cellular) oedema can result from toxic agents (including many in common use such as dinitrophenol (weight loss agent), hexachlorophene (disinfectant), and organophosphates including insecticides [28]), ischaemic stroke, or hypoxia; in cytotoxic oedema, the BBB may stay intact, but disturbance of cellular metabolism impairs ion transport in glial cell membranes, leading to cellular retention of sodium and water, and cell swelling especially in astrocytes in gray and white matters. Cytotoxic oedema may also be associated with a reduced ECS volume, further hindering diffusional transport of oedema fluid and solutes in the gray matter [82]. Vasogenic oedema results from breakdown of the BBB, e.g., associated with trauma, hypertension, osmotic imbalance, brain cancer, and brain inflammation (meningitis or encephalitis), allowing intravascular proteins and fluids into the parenchymal ECS. Several studies of vasogenic oedema models have demonstrated that bulk flow pathways, including white matter tracts and perivascular spaces, are important sites for oedema fluid movement and clearance (reviewed in [138]). Aquaporin water channels clearly play a role in the resolution of edema; in particular, AQP4 has been suggested to regulate ECS water in the healthy and diseased brain due to its localized expression on astrocytes at brain-CSF and blood-brain interfaces and demonstrated alterations in disease states [8]. Treatments based on mechanistic understanding may include intravascular mannitol and/or saline (osmotherapy), melatonin, and inhibitors of water channels (e.g., aquaporins) and ion cotransporters [47, 190]. Finally, decompressive craniectomy may be required in extreme/acute cases [23].

Prion diseases (or transmissible spongiform encephalopathies, TSE's) are a group of progressive neurodegenerative conditions, which unlike most infections which involve bacteria or viruses, involve misfolded protein [71, 197]. All known prion diseases in mammals affect brain structure, creating microscopic holes and hence a 'spongy' texture, with severe consequences for brain function. Prion diseases exist in both animals and humans. Scrapie, a disease affecting sheep and goats, was the first prion disease to be identified in the 1730s. In humans, the outbreak of Creutzfeldt-Jakob disease variant resulted from eating infected bovine-derived meat.

Prion-like spread of other CNS pathologies involving aggregated proteins is now recognised-for amyloid- $\beta$ (Alzheimer's disease), $\alpha$-synuclein (Parkinson's disease), and mutant Huntingtin (Huntington's disease) [14, 31], although the underlying mechanisms are not understood in detail [79, 85]. Extracellular vesicles (EVs) released from one cell and capable of influencing another (a known method of cell:cell communication) are recognised to be involved in the protein transmission in some of these neuropathies [106, 184], and also in tumours [29]. It is clear that the health of CSF and ISF flow and drainage will influence the spread of such aggregated proteins.

A recent analysis of abnormal phosphorylated tau (p-tau) deposition in samples from temporal cortex and adjacent white matter taken from patients with temporal lobe epilepsy (TLE) and chronic traumatic encephalopathy (CTE) has reported a similar pattern of pathological tau deposition in perivascular spaces in both conditions, suggesting similar underlying cerebrovascular pathology with abnormal perivascular p-tau accumulation as a potential mechanism [143]. Both TLE and CTE physiopathology involve neuronal death which likely initiates spillage of unbound tau protein into the extracellular space and, from there, to perivascular lining cells and perivascular spaces. 
Extracellular p-tau appeared to follow extracellular drainage pathways in the neuropil that led toward perivascular spaces bordering large ( $>100 \mu \mathrm{m}$ diameter) blood vessels; p-tau immunoreactivity was prominent within astroglial cells adjacent to blood vessels and frequently appeared clustered within the peri-venous space. Importantly, aggregated p-tau was detected in brain tissue from both CTE and TLE, but little was observed in control brain. Since larger aggregates of p-tau would not be as free to move readily through the brain ECS by diffusion as unbound monomers, such aggregates likely become trapped within the tissue, particularly the tissue space bordering venules and large veins; this sequence of events would be expected to further impede the subsequent clearance of $p$-tau and other waste constituents over time. Interestingly, military personnel exposed to blast shockwaves (e.g., from explosive devices) also show a characteristic pattern of GFAP and $\mathrm{p}$-tau immunoreactivity with prominent astroglial scarring at brain-fluid interfaces including the subpial region and perivascular spaces [156].

Perivascular accumulation of $\mathrm{p}$-tau is also observed in Alzheimer's disease and has been demonstrated to be present in arteries/arterioles as well as veins in the parenchyma [118]. Interestingly, perivascular amyloid beta deposits (cerebral amyloid angiopathy) within the tunica media of leptomeningeal arteries as well as cortical arteries, arterioles, and capillaries are among the classic neuropathological hallmarks of Alzheimer's disease, while veins and venules rarely exhibit such deposits [154]. Such characteristic amyloid beta accumulation in Alzheimer's disease has led some to suggest that this pathology results from failure of amyloid beta drainage out of the brain within the basement membranes of capillaries, arterioles and arteries [141]. However, it has also been suggested that this pattern of amyloid beta deposition could be due to abnormal perivascular amyloid beta entry and accumulation from the CSF into the brain [69, 137], consistent with reports that leptomeningeal arteries typically exhibit more cerebral amyloid angiopathy than penetrating cortical arteries [154]. Indeed, it is now increasingly appreciated that structural alterations in draining venules and veins also may play a role in the pathology of Alzheimer's disease [109], so the precise mechanisms at play in producing the perivascular pathology and amyloid deposition of Alzheimer's disease require further study.

Finally, it bears noting that an enlarged PVS has been identified (typically associated with larger caliber vessels such as perforating arterioles and venules) in a number of clinical MRI studies of patients with traumatic brain injuries [93], acute ischemic stroke [53], and multiple different types of mucopolysaccharidoses [115, 198]. Enlarged perivascular spaces might simplistically suggest either increased water secretion by the BBB, decreased clearance of CSF, increased resistance to the circulation/transport and/or drainage of perivascular fluid, or a combination of all of the above. The mechanism of increased production or decreased CSF absorption seems unlikely, at least in ageing-related small vessel ischemic disease, where ventricular size is commonly normal, so it is tempting to speculate that some form of hindrance or impedance of perivascular fluid circulation/ transport may underlie the enlarged PVS observed in this condition.

In summary, if cerebral regulation of fluid and waste elimination is disrupted, a dangerous cycle can emerge between impedance of waste clearance pathways and exacerbation of cerebral oedema or inflammation.

\section{Conclusions}

Therefore, to return to the question-does the 'glymphatic' system exist, in the form of AQP4-dependent convective flow pathways bathing neurons, synapses and glia in the parenchyma? It is becoming increasingly apparent that under normal conditions, such flows likely do not exist in the neuropil of the gray matter. Rather than a 'glymphatic' system as originally proposed [91, 124, 125], the weight of the evidence now suggests the existence of a perivascular fluid system for the CNS, with convective flow or dispersion along the perivascular spaces of larger vessels and then diffusion predominantly regulating CSF/ISF exchange at the level of the neurovascular unit associated with CNS microvessels, as now proposed by several groups $[6,74$, $80,96,137,161,162,192]$. It remains possible that pericapillary convection occurs in the basal lamina in addition to diffusion to formally link up the arteriolar and venular perivascular fluid compartments and allow a fully convective circulation pathway [74, 137]; regardless, CSF/ISF exchange may at least partly occur through the neuropil of the gray matter at the capillary level by diffusion, as neurons and all the other constituents of the NVU are not located further than about 10-20 $\mu \mathrm{m}$ from the pericapillary spaces, a distance that has likely been optimized for the effective diffusion of glucose, oxygen, and countless other substances from the circulation $[3,192]$.

In summary, the classical view of the system (pre-2012) together with recent studies supports the evidence for diffusion (not bulk flow) from capillaries and throughout the interstitium, the optimal arrangement for homeostasis of the neuronal microenvironment. This acts together with a well-regulated system of convective flow channels, where they are most needed and will least disturb neural function: (a) in the vascular system supplying arteries and ultimately capillaries and (b) in the perivascular space around large arteries and arterioles, extending down to the capillary level, carrying flow of a small volume of CSF from the brain surface into the brain. The PVS around venules 
and veins would appear to collect fluid drainage from the interstitium and channel it out of the parenchyma, partly back to the CSF in the SAS but also to other sites; in addition, there is some seepage of fluid drainage across the ependyma into the ventricles. The net result is wellmaintained homeostasis of the neural microenvironment, efficient (and sufficient) communication between CSF produced by the CP and the brain parenchyma, and efficient clearance of cell debris and waste products of metabolism which are too large to exit across the endothelium of the blood vessels. Clearly, much more work is needed to resolve current discrepancies surrounding many other aspects of the system, perhaps most notably the effect that different anaesthetics, natural sleep and wakefulness may have on convective and diffusive transport in the PVS and ECS, respectively. More sophisticated quantitative modelling of such transport is urgently needed and will likely play a larger role in the future to better clarify some of the discrepancies and to suggest new experiments that may help to resolve them.

In several pathologies, disturbances of any element of this system can result in brain fluid accumulation and oedema. In many cases, the oedema is local and resolved by endogenous repair mechanisms; in more severe cases, medical/ surgical intervention may be required. Recovery of brain function can involve adjustments in the vascular and brain fluid flow channels and neuronal plasticity to compensate at least in part for damaged circuits. It is clear that maintaining some form of healthy perivascular fluid circulation and at least some degree of CSF/ISF exchange, as well as a healthy cardiovascular system, are important in preserving effective CNS function into old age.

Acknowledgements This work was supported by the University of Wisconsin-Madison School of Pharmacy, the Graduate School at the University of Wisconsin, the Michael J. Fox Foundation for Parkinson's Research (Therapeutic Pipeline Grant Award-RGT), and the Clinical and Translational Science Award (CTSA) program, administered through the NIH National Center for Advancing Translational Sciences (NIH UL1TR000427 and KL2TR00428-RGT). All content is solely the responsibility of the authors and does not necessarily represent the official views of the NIH. Support also came from a National Science Foundation Graduate Research Fellowship under Grant No. DGE-1256259 (MEP) and an NIH-supported predoctoral training grant fellowship administered through the University of WisconsinMadison Clinical Neuroengineering Training Program (NRSA T32 EBO11434-MEP). NJA and JEP received current research support from The Medical Research Council, UK and from UCB. RGT, NJA, and JEP acknowledge (1) periodically receiving honoraria for speaking to organizations within academia, foundations, and the biotechnology and pharmaceutical industry and (2) occasional service as a consultant to industry on CNS drug delivery.

Open Access This article is distributed under the terms of the Creative Commons Attribution 4.0 International License (http://creativeco mmons.org/licenses/by/4.0/), which permits unrestricted use, distribution, and reproduction in any medium, provided you give appropriate credit to the original author(s) and the source, provide a link to the Creative Commons license, and indicate if changes were made.

\section{References}

1. Abbott NJ (2004) Evidence for bulk flow of brain interstitial fluid: significance for physiology and pathology. Neurochem Int 45:545-552. https://doi.org/10.1016/j.neuint.2003.11.006

2. Abbott NJ (2013) Blood-brain barrier structure and function and the challenges for CNS drug delivery. J Inherit Metab Dis 36:437-449. https://doi.org/10.1007/s10545-013-9608-0

3. Abbott NJ, Rönnbäck L, Hansson E (2006) Astrocyte-endothelial interactions at the blood-brain barrier. Nat Rev Neurosci 7:4153. https://doi.org/10.1038/nrn1824

4. Alcolado R, Weller RO, Parrish EP, Garrod D (1988) The cranial arachnoid and pia mater in man: anatomical and ultrastructural observations. Neuropathol Appl Neurobiol 14:1-17. https://doi. org/10.1111/j.1365-2990.1988.tb00862.x

5. Ames A, Higashi K, Nesbett FB (1965) Relation of potassium concentration in choroidplexus fluid to that in plasma. J Physiol 181:506-515

6. Asgari M, de Zélicourt D, Kurtcuoglu V (2016) Glymphatic solute transport does not require bulk flow. Sci Rep 6:38635. https ://doi.org/10.1038/srep38635

7. Aspelund A, Antila S, Proulx ST, Karlsen TV, Karaman S, Detmar M, Wiig H, Alitalo K (2015) A dural lymphatic vascular system that drains brain interstitial fluid and macromolecules. J Exp Med 212:991-999. https://doi.org/10.1084/jem.20142290

8. Badaut J, Fukuda AM, Jullienne A, Petry KG (2014) Aquaporin and brain diseases. Biochim Biophys Acta Gen Subj 1840:15541565. https://doi.org/10.1016/j.bbagen.2013.10.032

9. Badaut J, Lasbennes F, Magistretti PJ, Regli L (2002) Aquaporins in brain: distribution, physiology, and pathophysiology. J Cereb Blood Flow Metab 22:367-378. https://doi.org/10.1097/00004 647-200204000-00001

10. Barkai A, Glusman M, Rapport MM (1972) Serotonin turnover in the intact cat brain. J Pharmacol Exp Ther 181:28-35

11. Barresi R, Campbell KP (2006) Dystroglycan: from biosynthesis to pathogenesis of human disease. J Cell Sci 119:199-207. https ://doi.org/10.1242/jcs.02814

12. Bateman GA, Brown KM (2012) The measurement of CSF flow through the aqueduct in normal and hydrocephalic children: from where does it come, to where does it go? Childs Nerv Syst 28:55-63. https://doi.org/10.1007/s00381-011-1617-4

13. Bauer HJ (1993) The Quincke centennial lecture. In: Felgenhauer $\mathrm{K}$, Holzgraefe M, Prange $\mathrm{H}$ (eds) CNS barriers mod diagnostics. VCH, Weinheim, pp 27-32

14. Borghammer P (2017) How does parkinson's disease begin? Perspectives on neuroanatomical pathways, prions, and histology. Mov Disord. https://doi.org/10.1002/mds.27138

15. Borlongan CV, Skinner SJM, Geaney M, Vasconcellos AV, Elliott RB, Emerich DF (2004) Intracerebral transplantation of porcine choroid plexus provides structural and functional neuroprotection in a rodent model of stroke. Stroke 35:2206-2210. https://doi. org/10.1161/01.STR.0000138954.25825.0b

16. Bradbury MW, Cserr HF, Westrop RJ (1981) Drainage of cerebral interstitial fluid into deep cervical lymph of the rabbit. Am J Physiol 240:F329-F336

17. Bradbury MW, Westrop RJ (1983) Factors influencing exit of substances from cerebrospinal fluid into deep cervical lymph of the rabbit. J Physiol 339:519-534 
18. Brierley JB (1950) The penetration of particulate matter from the cerebrospinal fluid into the spinal ganglia, peripheral nerves, and perivascular spaces of the central nervous system. J Neurol Neurosurg Psychiatry 13:203-215

19. Brightman MW (1968) The intracerebral movement of proteins injected into blood and cerebrospinal fluid of mice. Prog Brain Res 29:19-40. https://doi.org/10.1016/S0079-6123(08)64147-3

20. Brightman MW (2002) The brain's interstitial clefts and their glial walls. J Neurocytol 31:595-603

21. Brightman MW, Reese TS (1969) Junctions between intimately apposed cell membranes in the vertebrate brain. J Cell Biol 40:648-677. https://doi.org/10.1083/jcb.40.3.648

22. Brinker T, Stopa E, Morrison J, Klinge P (2014) A new look at cerebrospinal fluid circulation. Fluids Barriers CNS 11:10. https ://doi.org/10.1186/2045-8118-11-10

23. Brown DA, Wijdicks EFM (2017) Decompressive craniectomy in acute brain injury. Crit Care Neurol Part I. https://doi. org/10.1016/b978-0-444-63600-3.00016-7

24. Carare RO, Bernardes-Silva M, Newman TA, Page AM, Nicoll JAR, Perry VH, Weller RO (2008) Solutes, but not cells, drain from the brain parenchyma along basement membranes of capillaries and arteries: significance for cerebral amyloid angiopathy and neuroimmunology. Neuropathol Appl Neurobiol 34:131144. https://doi.org/10.1111/j.1365-2990.2007.00926.x

25. Chen RL, Athauda SBP, Kassem NA, Zhang Y, Segal MB, Preston JE (2005) Decrease of transthyretin synthesis at the bloodcerebrospinal fluid barrier of old sheep. J Gerontol A Biol Sci Med Sci 60:852-858

26. Chen RL, Kassem NA, Sadeghi M, Preston JE (2008) Insulin-like growth factor-II uptake into choroid plexus and brain of young and old sheep. J Gerontol A Biol Sci Med Sci 63:141-148

27. Chen RL, Sage EA, Dunn MJ, Wait R, Preston JE (2006) Optimising ovine cerebrospinal fluid preparation for two-dimensional gel electrophoresis. Proteomics 6:3170-3175. https://doi. org/10.1002/pmic.200500623

28. Chen Y (2012) Organophosphate-induced brain damage: mechanisms, neuropsychiatric and neurological consequences, and potential therapeutic strategies. Neurotoxicology 33:391-400. https://doi.org/10.1016/j.neuro.2012.03.011

29. Choi D, Lee TH, Spinelli C, Chennakrishnaiah S, D'Asti E, Rak J (2017) Extracellular vesicle communication pathways as regulatory targets of oncogenic transformation. Semin Cell Dev Biol 67:11-22. https://doi.org/10.1016/j.semcdb.2017.01.003

30. Cloyd MW, Low FN (1974) Scanning electron microscopy of the subarachnoid space in the dog. I. Spinal cord levels. J Comp Neurol 153:325-368. https://doi.org/10.1002/cne.901530402

31. Costanzo M, Zurzolo C (2013) The cell biology of prion-like spread of protein aggregates: mechanisms and implication in neurodegeneration. Biochem J 452:1-17. https://doi.org/10.1042/ BJ20121898

32. Cserr HF (1974) Relationship between cerebrospinal fluid and interstitial fluid of brain. Fed Proc 33:2075-2078

33. Cserr HF, Cooper DN, Milhorat TH (1977) Flow of cerebral interstitial fluid as indicated by the removal of extracellular markers from rat caudate nucleus. Exp Eye Res 25(Suppl):461-473. https://doi.org/10.1016/S0014-4835(77)80041-9

34. Cserr HF, Cooper DN, Suri PK, Patlak CS (1981) Efflux of radiolabeled polyethylene glycols and albumin from rat brain. Am J Physiol 240:F319-F328

35. Cserr HF, Depasquale M, Patlak CS, Pullen RG (1986) Convection of cerebral interstitial fluid and its role in brain volume regulation. Ann N Y Acad Sci 481:123-134

36. Cserr HF, Ostrach LH (1974) Bulk flow of interstitial fluid after intracranial injection of blue dextran 2000. Exp Neurol 45:50-60. https://doi.org/10.1016/0014-4886(74)90099-5
37. Cserr HF, Patlak CS (1992) Secretion and bulk flow of interstitial fluid. In: Bradbury MW (ed) Physiology and pharmacology of the blood-brain barrier. Springer, Berlin, pp 245-261

38. Cushing H (1914) Studies on the cerebro-spinal fluid: I. Introduction. J Med Res 31:1-19

39. Cutler RW, Deuel RK, Barlow CF (1967) Albumin exchange between plasma and cerebrospinal fluid. Arch Neurol 17:261-270

40. Dandy WE (1919) Experimental hydrocephalus. Ann Surg 70:129-142

41. Davson H (1967) Physiology of the cerebrospinal fluid. Churchill, London

42. Davson H, Kleeman CR, Levin E (1962) Quantitative studies of the passage of different substances out of the cerebrospinal fluid. J Physiol 161:126-142

43. Davson H, Segal MB (1970) The effects of some inhibitors and accelerators of sodium transport on the turnover of ${ }^{22} \mathrm{Na}$ in the cerebrospinal fluid and the brain. J Physiol 209:131-153

44. Davson H, Segal MB (1995) Phyioslogy of the CSF and bloodbrain barriers, 1 st edn. CRC Press Inc, Boca Raton

45. Davson H, Welch K, Segal MB (1987) Physiology and pathophysiology of the cerebrospinal fluid. Churchill Livingstone, Edinburgh

46. Deisenhammer F (2015) The history of cerebrospinal fluid. In: Deisenhammer F, Sellebjerg F, Teunissen C, Tumani H (eds) Cerebrospinal fluid in clinical neurology. Springer International Publishing, Cham, pp 3-16

47. Deng YY, Shen FC, Xie D, Han QP, Fang M, Chen CB, Zeng HK (2016) Progress in drug treatment of cerebral edema. Mini Rev Med Chem 16:917-925

48. Diem AK, MacGregor Sharp M, Gatherer M, Bressloff NW, Carare RO, Richardson G (2017) Arterial pulsations cannot drive intramural periarterial drainage: significance for $A \beta$ drainage. Front Neurosci 11:475. https://doi.org/10.3389/fnins.2017.00475

49. Dilmen N (2005) MRI showing pulsation of CSF. https://commo ns.wikimedia.org/wiki/File:NPH_MRI_272_GILD.gif. Accessed 2 Oct 2017

50. Ding F, O'donnell J, Xu Q, Kang N, Goldman N, Nedergaard $M$ (2016) Changes in the composition of brain interstitial ions control the sleep-wake cycle. Science (80-) 352:550-555. https ://doi.org/10.1126/science.aad4821

51. Dolman D, Drndarski S, Abbott NJ, Rattray M (2005) Induction of aquaporin 1 but not aquaporin 4 messenger RNA in rat primary brain microvessel endothelial cells in culture. J Neurochem 93:825-833. https://doi.org/10.1111/j.1471-4159.2005.03111.x

52. Doran A, Obach RS, Smith BJ, Hosea NA, Becker S, Callegari E, Chen C, Chen X, Choo E, Cianfrogna J, Cox LM, Gibbs JP, Gibbs MA, Hatch H, Hop CECA, Kasman IN, Laperle J, Liu J, Liu X, Logman M, Maclin D, Nedza FM, Nelson F, Olson E, Rahematpura S, Raunig D, Rogers S, Schmidt K, Spracklin DK, Szewc M, Troutman M, Tseng E, Tu M, Van Deusen JW, Venkatakrishnan K, Walens G, Wang EQ, Wong D, Yasgar AS, Zhang C (2005) The impact of P-glycoprotein on the disposition of drugs targeted for indications of the central nervous system: evaluation using the MDR1A/1B knockout mouse model. Drug Metab Dispos 33:165-174. https://doi.org/10.1124/ dmd.104.001230

53. Doubal FN, MacLullich AMJ, Ferguson KJ, Dennis MS, Wardlaw JM (2010) Enlarged perivascular spaces on MRI are a feature of cerebral small vessel disease. Stroke 41:450-454. https ://doi.org/10.1161/STROKEAHA.109.564914

54. Dreha-Kulaczewski S, Joseph AA, Merboldt K-D, Ludwig H-C, Gärtner J, Frahm J (2015) Inspiration is the major regulator of human CSF flow. J Neurosci 35:2485-2491. https://doi. org/10.1523/JNEUROSCI.3246-14.2015 
55. Dreier JP, Lemale CL, Kola V, Friedman A, Schoknecht K (2017) Spreading depolarization is not an epiphenomenon but the principal mechanism of the cytotoxic edema in various gray matter structures of the brain during stroke. Neuropharmacology. https ://doi.org/10.1016/j.neuropharm.2017.09.027

56. Dubocovich ML, Hudson RL, Sumaya IC, Masana MI, Manna E (2005) Effect of MT1 melatonin receptor deletion on melatonin-mediated phase shift of circadian rhythms in the C57BL/6 mouse. J Pineal Res 39:113-120. https://doi.org/10.1111/j.1600079X.2005.00230.x

57. Engelhardt B, Carare RO, Bechmann I, Flügel A, Laman JD, Weller RO (2016) Vascular, glial, and lymphatic immune gateways of the central nervous system. Acta Neuropathol 132:317338. https://doi.org/10.1007/s00401-016-1606-5

58. Engelhardt B, Vajkoczy P, Weller RO (2017) The movers and shapers in immune privilege of the CNS. Nat Immunol 18:123-131

59. Faber WM (1937) The nasal mucosa and the subarachnoid space. Am J Anat 62:121-148. https://doi.org/10.1002/aja.1000620106

60. Fenstermacher JD, Patlak CS (1976) The movements of water and solutes in the brains of mammals. In: Pappius HM, Feindel W (eds) Dynamics of brain edema. Springer, Berlin, pp 87-94

61. Földi M (1996) The brain and the lymphatic system (I). Lymphology 29:1-9

62. Förster C (2008) Tight junctions and the modulation of barrier function in disease. Histochem Cell Biol 130:55-70. https://doi. org/10.1007/s00418-008-0424-9

63. Frederickson RG, Low FN (1969) Blood vessels and tissue space associated with the brain of the rat. Am J Anat 125:123145. https://doi.org/10.1002/aja.1001250202

64. Gaete PS, Lillo MA, Figueroa XF (2014) Functional role of connexins and pannexins in the interaction between vascular and nervous system. J Cell Physiol 229:1336-1345. https://doi. org/10.1002/jcp. 24563

65. Gakuba C, Gaberel T, Goursaud S, Bourges J, di Palma C, Quenault A, de Lizarrondo SM, Vivien D, Gauberti M (2018) General anesthesia inhibits the activity of the "glymphatic system". Theranostics 8:710-722. https://doi.org/10.7150/ thno. 19154

66. Galea I, Bechmann I, Perry VH (2007) What is immune privilege (not)? Trends Immunol 28:12-18. https://doi. org/10.1016/j.it.2006.11.004

67. Gess B, Sevimli S, Strecker J-K, Young P, Schäbitz W-R (2011) Sodium-dependent vitamin C transporter 2 (SVCT2) expression and activity in brain capillary endothelial cells after transient ischemia in mice. PLoS One 6:e17139. https://doi. org/10.1371/journal.pone.0017139

68. Ghersi-Egea JF, Finnegan W, Chen JL, Fenstermacher JD, Hospital HF (1996) Rapid distribution of intraventricularly administered sucrose into cerebrospinal fluid cisterns via subarachnoid velae in rat. Neuroscience 75:1271-1288. https://doi. org/10.1016/0306-4522(96)00281-3

69. Ghersi-Egea JF, Gorevic PD, Ghiso J, Frangione B, Patlak CS, Fenstermacher JD (1996) Fate of cerebrospinal fluidborne amyloid beta-peptide: rapid clearance into blood and appreciable accumulation by cerebral arteries. J Neurochem 67:880-883. https://doi.org/10.1046/j.1471-4159.1996.67020 880.x

70. Greenberg SM, Salman RAS, Biessels GJ, van Buchem M, Cordonnier C, Lee J, Montaner J, Schneider JA, Smith EE, Vernooij M, Werring DJ (2014) Outcome markers for clinical trials in cerebral amyloid angiopathy. Lancet Neurol 13:419-428. https ://doi.org/10.1016/S1474-4422(14)70003-1

71. Griffoni C, Toni M, Spisni E, Bianco M, Santi S, Riccio M, Tomasi V (2003) The cellular prion protein: biochemistry, topology, and physiologic functions. Cell Biochem Biophys 38:287-304

72. Gutiérrez AM, González E, Echevarría M, Hernández CS, Whittembury G (1995) The proximal straight tubule (PST) basolateral cell membrane water channel: selectivity characteristics. J Membr Biol 143:189-197

73. Haj-Yasein NN, Vindedal GF, Eilert-Olsen M, Gundersen GA, Skare $\varnothing$, Laake P, Klungland A, Thorén AE, Burkhardt JM, Ottersen OP, Nagelhus EA (2011) Glial-conditional deletion of aquaporin-4 (Aqp4) reduces blood-brain water uptake and confers barrier function on perivascular astrocyte endfeet. Proc Natl Acad Sci USA 108:17815-17820. https://doi.org/10.1073/ pnas. 1110655108

74. Hannocks M-J, Pizzo ME, Huppert J, Despande T, Abbott NJ, Thorne RG, Sorokin L (2017) Molecular characterization of perivascular drainage pathways in the murine brain. J Cereb Blood Flow Metab. https://doi.org/10.1177/0271678X17749689

75. Van Harreveld A (1972) The extracellular space in the vertebrate central nervous system. In: Bourne G (ed) The structure and function of nervous tissue, vol 4. Academic Press, New York, pp 447-511

76. Härtig W, Derouiche A, Welt K, Brauer K, Grosche J, Mäder M, Reichenbach A, Brückner G (1999) Cortical neurons immunoreactive for the potassium channel $\mathrm{Kv} 3.1 \mathrm{~b}$ subunit are predominantly surrounded by perineuronal nets presumed as a buffering system for cations. Brain Res 842:15-29. https://doi.org/10.1016/ S0006-8993(99)01784-9

77. Hladky SB, Barrand MA (2014) Mechanisms of fluid movement into, through and out of the brain: evaluation of the evidence. Fluids Barriers CNS 11:26. https://doi. org/10.1186/2045-8118-11-26

78. Hladky SB, Barrand MA (2016) Fluid and ion transfer across the blood-brain and blood-cerebrospinal fluid barriers; a comparative account of mechanisms and roles. Fluids Barriers CNS 13:19. https://doi.org/10.1186/s12987-016-0040-3

79. Holmes BB, Diamond MI (2012) Cellular mechanisms of protein aggregate propagation. Curr Opin Neurol 25:721-726. https://doi.org/10.1097/WCO.0b013e32835a3ee0

80. Holter KE, Kehlet B, Devor A, Sejnowski TJ, Dale AM, Omholt SW, Ottersen OP, Nagelhus EA, Mardal K-A, Pettersen KH (2017) Interstitial solute transport in 3D reconstructed neuropil occurs by diffusion rather than bulk flow. Proc Natl Acad Sci USA 114:9894-9899. https://doi.org/10.1073/pnas.17069 42114

81. Horstmann E, Meves H (1959) Die Feinstruktur des molekularen Rindengraues und ihre physiologische Bedeutung. Zeitschrift für Zellforsch und Mikroskopische Anat 49:569604. https://doi.org/10.1007/BF00338866

82. Hossmann KA (1976) Development and resolution of ischemic brain swelling. In: Pappius HM, Feindel W (eds) Dynamics of brain edema. Springer, Berlin, pp 219-227

83. Hrabetová S, Masri D, Tao L, Xiao F, Nicholson C (2009) Calcium diffusion enhanced after cleavage of negatively charged components of brain extracellular matrix by chondroitinase ABC. J Physiol 587:4029-4049. https://doi.org/10.1113/jphys iol.2009.170092

84. Hsu Y, Tran M, Linninger AA (2015) Dynamic regulation of aquaporin-4 water channels in neurological disorders. Croat Med J 56:401-421. https://doi.org/10.3325/cmj.2015.56.401

85. Huang W-J, Chen W-W, Zhang X (2015) Prions mediated neurodegenerative disorders. Eur Rev Med Pharmacol Sci 19:4028-4034

86. Huber JD, Egleton RD, Davis TP (2001) Molecular physiology and pathophysiology of tight junctions in the blood-brain barrier. Trends Neurosci 24:719-725 
87. Iadecola C (2013) The pathobiology of vascular dementia. Neuron 80:844-866. https://doi.org/10.1016/j.neuro n.2013.10.008

88. Ichimura T, Fraser PAA, Cserr HF (1991) Distribution of extracellular tracers in perivascular spaces of the rat brain. Brain Res 545:103-113. https://doi.org/10.1016/0006-8993(91)91275-6

89. Iliff JJ, Lee H, Yu M, Feng T, Logan J, Nedergaard M, Benveniste H (2013) Brain-wide pathway for waste clearance captured by contrast-enhanced MRI. J Clin Invest 123:1299-1309. https:// doi.org/10.1172/JCI67677

90. Iliff JJ, Nedergaard M (2013) Is there a cerebral lymphatic system? Stroke 44:S93-S95. https://doi.org/10.1161/STROK EAHA.112.678698

91. Iliff JJ, Wang M, Liao Y, Plogg BA, Peng W, Gundersen GA, Benveniste H, Vates GE, Deane R, Goldman SA, Nagelhus EA, Nedergaard M (2012) A paravascular pathway facilitates CSF flow through the brain parenchyma and the clearance of interstitial solutes, including amyloid $\beta$. Sci Transl Med 4:147ra111. https://doi.org/10.1126/scitranslmed.3003748

92. Iliff JJ, Wang M, Liao Y, Plogg BA, Peng W, Gundersen GA, Benveniste H, Vates GE, Deane R, Goldman SA, Nagelhus EA, Nedergaard M (2012) A paravascular pathway facilitates CSF flow through the brain parenchyma and the clearance of interstitial solutes, including amyloid $\beta$. Sci Transl Med. https://doi. org/10.1126/scitranslmed.3003748

93. Inglese M, Bomsztyk E, Gonen O, Mannon LJ, Grossman RI, Rusinek H (2005) Dilated perivascular spaces: Hallmarks of mild traumatic brain injury. Am J Neuroradiol 26:719-724. http:// www.ajnr.org/content/26/4/719

94. Janzen W (1961) The relationship between the perivascular and the subarachnoidal space. Psychiatr Neurol Neurochir 64:37-45

95. Jessen NA, Munk ASF, Lundgaard I, Nedergaard M (2015) The glymphatic system: a beginner's guide. Neurochem Res 40:1-17. https://doi.org/10.1007/s11064-015-1581-6

96. Jin B-J, Smith AJ, Verkman AS (2016) Spatial model of convective solute transport in brain extracellular space does not support a "glymphatic" mechanism. J Gen Physiol 148:489-501. https:// doi.org/10.1085/jgp.201611684

97. Jones EG (1970) On the mode of entry of blood vessels into the cerebral cortex. J Anat 106:507-520

98. Jung JS, Bhat RV, Preston GM, Guggino WB, Baraban JM, Agre $P$ (1994) Molecular characterization of an aquaporin cDNA from brain: candidate osmoreceptor and regulator of water balance. Proc Natl Acad Sci USA 91:13052-13056. https://doi. org/10.1073/pnas.91.26.13052

99. Kalimo H, Fredriksson K, Nordborg C, Auer RN, Olsson Y, Johansson B (1986) The spread of brain oedema in hypertensive brain injury. Med Biol 64:133-137

100. Kervezee L, Hartman R, van den Berg D-J, Shimizu S, EmotoYamamoto Y, Meijer JH, de Lange ECM (2014) Diurnal variation in P-glycoprotein-mediated transport and cerebrospinal fluid turnover in the brain. AAPS J 16:1029-1037. https://doi. org/10.1208/s12248-014-9625-4

101. Kida S, Pantazis A, Weller RO (1993) CSF drains directly from the subarachnoid space into nasal lymphatics in the rat. Anatomy, histology and immunological significance. Neuropathol Appl Neurobiol 19:480-488. https://doi. org/10.1111/j.1365-2990.1993.tb00476.x

102. Kinney JP, Spacek J, Bartol TM, Bajaj CL, Harris KM, Sejnowski TJ (2013) Extracellular sheets and tunnels modulate glutamate diffusion in hippocampal neuropil. J Comp Neurol 521:448-464. https://doi.org/10.1002/cne.23181

103. Koh L, Zakharov A, Johnston M (2005) Integration of the subarachnoid space and lymphatics: is it time to embrace a new concept of cerebrospinal fluid absorption? Cereb Fluid Res 2:6. https ://doi.org/10.1186/1743-8454-2-6
104. Konsman JP, Tridon V, Dantzer R (2000) Diffusion and action of intracerebroventricularly injected interleukin-1 in the CNS. Neuroscience 101:957-967. https://doi.org/10.1016/S0306 $-4522(00) 00403-6$

105. Korogod N, Petersen CCH, Knott GW (2015) Ultrastructural analysis of adult mouse neocortex comparing aldehyde perfusion with cryo fixation. Elife 4:1-17. https://doi.org/10.7554/ eLife.05793

106. Krämer-Albers E-M, Hill AF (2016) Extracellular vesicles: interneural shuttles of complex messages. Curr Opin Neurobiol 39:101-107. https://doi.org/10.1016/j.conb.2016.04.016

107. Krisch B, Leonhardt H, Oksche A (1983) The meningeal compartments of the median eminence and the cortex. A comparative analysis in the rat. Cell Tissue Res 228:597-640

108. Krisch B, Leonhardt H, Oksche A (1984) Compartments and perivascular arrangement of the meninges covering the cerebral cortex of the rat. Cell Tissue Res 238:459-474

109. Lai AY, Dorr A, Thomason LAM, Koletar MM, Sled JG, Stefanovic B, McLaurin J (2015) Venular degeneration leads to vascular dysfunction in a transgenic model of Alzheimer's disease. Brain 138:1046-1058. https://doi.org/10.1093/brain/awv023

110. Legros C, Chesneau D, Boutin JA, Barc C, Malpaux B (2014) Melatonin from cerebrospinal fluid but not from blood reaches sheep cerebral tissues under physiological conditions. J Neuroendocrinol 26:151-163. https://doi.org/10.1111/jne.12134

111. Levin VA, Fenstermacher JD, Patlak CS (1970) Sucrose and inulin space measurements of cerebral cortex in four mammalian species. Am J Physiol 219:1528-1533

112. Lochhead JJ, Wolak DJ, Pizzo ME, Thorne RG (2015) Rapid transport within cerebral perivascular spaces underlies widespread tracer distribution in the brain after intranasal administration. J Cereb Blood Flow Metab 35:371-381. https://doi. org/10.1038/jcbfm.2014.215

113. Louveau A, Smirnov I, Keyes TJ, Eccles JD, Rouhani SJ, Peske JD, Derecki NC, Castle D, Mandell JW, Lee KS, Harris TH, Kipnis J (2015) Structural and functional features of central nervous system lymphatic vessels. Nature 523:337-341. https://doi. org/10.1038/nature 14432

114. Mathiisen TM, Lehre KP, Danbolt NC, Ottersen OP (2010) The perivascular astroglial sheath provides a complete covering of the brain microvessels: an electron microscopic 3D reconstruction. Glia 58:1094-1103. https://doi.org/10.1002/glia.20990

115. Matsubara Y, Miyazaki O, Kosuga M, Okuyama T, Nosaka S (2017) Cerebral magnetic resonance findings during enzyme replacement therapy in mucopolysaccharidosis. Pediatr Radiol 47:1-11. https://doi.org/10.1007/s00247-017-3935-5

116. McConnell H (1994) Historical perspective. In: McConnell H, Bianchine JR (eds) Cerebrospinal fluid in neurology and psychiatry. Springer, Boston, pp 1-4

117. Mehta D, Malik AB (2006) Signaling mechanisms regulating endothelial permeability. Physiol Rev 86:279-367. https://doi. org/10.1152/physrev.00012.2005

118. Merlini M, Wanner D, Nitsch RM (2016) Tau pathologydependent remodelling of cerebral arteries precedes Alzheimer's disease-related microvascular cerebral amyloid angiopathy. Acta Neuropathol 131:737-752. https://doi.org/10.1007/s0040 1-016-1560-2

119. Milhorat TH (1969) Choroid plexus and cerebrospinal fluid production. Science 166:1514-1516

120. Morris AWJ, Sharp MM, Albargothy NJ, Fernandes R, Hawkes CA, Verma A, Weller RO, Carare RO (2016) Vascular basement membranes as pathways for the passage of fluid into and out of the brain. Acta Neuropathol. https://doi.org/10.1007/s0040 1-016-1555-z

121. Muldoon LL, Alvarez JI, Begley DJ, Boado RJ, del Zoppo GJ, Doolittle ND, Engelhardt B, Hallenbeck JM, Lonser RR, Ohlfest 
JR, Prat A, Scarpa M, Smeyne RJ, Drewes LR, Neuwelt EA (2013) Immunologic privilege in the central nervous system and the blood-brain barrier. J Cereb Blood Flow Metab 33:13-21. https://doi.org/10.1038/jcbfm.2012.153

122. Murphy JB, Sturm E (1922) Homoplastic and heteroplastic tumor grafts in the brain. J Am Med Assoc 79:2159-2160. https://doi. org/10.1001/jama.1922.02640260031012

123. Nag S, Manias JL, Stewart DJ (2009) Pathology and new players in the pathogenesis of brain edema. Acta Neuropathol 118:197217. https://doi.org/10.1007/s00401-009-0541-0

124. Nedergaard M (2013) Neuroscience. Garbage truck of the brain. Science 340:1529-1530. https://doi.org/10.1126/science.12405 14

125. Nedergaard M, Goldman SA (2016) Brain drain. Sci Am 314:4449. https://doi.org/10.2753/JES1097-203X370202

126. Nicholson C, Phillips JM (1981) Ion diffusion modified by tortuosity and volume fraction in the extracellular microenvironment of the rat cerebellum. J Physiol 321:225-257

127. Nicholson C, Tao L (1993) Hindered diffusion of high molecular weight compounds in brain extracellular microenvironment measured with integrative optical imaging. Biophys J 65:22772290. https://doi.org/10.1016/S0006-3495(93)81324-9

128. Nielsen S, Nagelhus EA, Amiry-Moghaddam M, Bourque C, Agre P, Ottersen OP (1997) Specialized membrane domains for water transport in glial cells: high-resolution immunogold cytochemistry of aquaporin-4 in rat brain. J Neurosci 17:171-180

129. Nilsson C, Ståhlberg F, Thomsen C, Henriksen O, Herning M, Owman C (1992) Circadian variation in human cerebrospinal fluid production measured by magnetic resonance imaging. Am J Physiol 262:R20-R24

130. Nualart $F$ (2014) Vitamin $C$ transporters, recycling and the bystander effect in the nervous system: SVCT2 versus gluts. J Stem Cell Res Ther. https://doi.org/10.4172/2157-7633.10002 09

131. Ohata K, Marmarou A (1992) Clearance of brain edema and macromolecules through the cortical extracellular space. J Neurosurg 77:387-396. https://doi.org/10.3171/jns.1992.77.3.0387

132. Ohata K, Marmarou A, Povlishock JT (1990) An immunocytochemical study of protein clearance in brain infusion edema. Acta Neuropathol 81:162-177. https://doi.org/10.1007/BF00334505

133. Oldendorf WH, Davson H (1967) Brain extracellular space and the sink action of cerebrospinal fluid: measurement of rabbit brain extracellular space using sucrose labeled with carbon 14. Arch Neurol 17:196-205. https://doi.org/10.1001/archn eur.1967.00470260086010

134. Papadopoulos MC, Manley GT, Krishna S, Verkman AS (2004) Aquaporin-4 facilitates reabsorption of excess fluid in vasogenic brain edema. FASEB J 18:1291-1293. https://doi.org/10.1096/ fj.04-1723fje

135. Patlak CS, Fenstermacher JD (1975) Measurements of dog blood-brain transfer constants by ventriculocisternal perfusion. Am J Physiol 229:877-884

136. Peters A, Palay SSL, Webster HD (1991) The fine structure of the nervous system: neurons and their supporting cells, 3rd edn. Oxford University Press, New York

137. Pizzo M, Wolak DJ, Kumar NN, Brunette E, Brunnquell CL, Hannocks M-J, Abbott NJ, Meyerand ME, Sorokin L, Stanimirovic DB, Thorne RG (2017) Intrathecal antibody distribution in the rat brain: surface diffusion, perivascular transport, and osmotic enhancement of delivery. J Physiol. https://doi. org/10.1113/JP275105

138. Pizzo ME, Thorne RG (2017) The extracellular and perivascular spaces of the brain. In: Badaut J, Plesnila N (eds) Brain edema: from molecular mechanisms to clinical practice, 1st edn. Elsevier (Imprint: Academic Press), London, pp 103-128
139. Pollay M, Curl F (1967) Secretion of cerebrospinal fluid by the ventricular ependyma of the rabbit. Am J Physiol 213:1031-1038.

140. Prell GD, Khandelwal JK, Burns RS, Green JP (1989) Diurnal fluctuation in levels of histamine metabolites in cerebrospinal fluid of rhesus monkey. Agents Actions 26:279-286

141. Preston SD, Steart PV, Wilkinson A, Nicoll JA, Weller RO (2003) Capillary and arterial cerebral amyloid angiopathy in Alzheimer's disease: defining the perivascular route for the elimination of amyloid beta from the human brain. Neuropathol Appl Neurobiol 29:106-117. https://doi.org/10.104 6/j.1365-2990.2003.00424.x

142. Proescholdt MG, Hutto B, Brady LS, Herkenham M (2000) Studies of cerebrospinal fluid flow and penetration into brain following lateral ventricle and cisterna magna injections of the tracer [14C] inulin in rat. Neuroscience 95:577-592. https://doi. org/10.1016/S0306-4522(99)00417-0

143. Puvenna V, Engeler M, Banjara M, Brennan C, Schreiber P, Dadas A, Bahrami A, Solanki J, Bandyopadhyay A, Morris JK, Bernick C, Ghosh C, Rapp E, Bazarian JJ, Janigro D (2016) Is phosphorylated tau unique to chronic traumatic encephalopathy? Phosphorylated tau in epileptic brain and chronic traumatic encephalopathy. Brain Res 1630:225-240. https://doi. org/10.1016/j.brainres.2015.11.007

144. Rall DP, Oppelt WW, Patlak CS (1962) Extracellular space of brain as determined by diffusion of inulin from the ventricular system. Life Sci 1:43-48. https://doi.org/10.1016/00243205(62)90104-2

145. Rapoport SI, Schapiro MB, May C (2004) Reduced brain delivery of homovanillic acid to cerebrospinal fluid during human aging. Arch Neurol 61:1721-1724. https://doi.org/10.1001/archn eur.61.11.1721

146. Reina MA, De Casasola ODL, Villanueva MC, López A, Machés F, De Andrés JA (2004) Ultrastructural findings in human spinal pia mater in relation to subarachnoid anesthesia. Anesth Analg 98:1479-1485. https://doi.org/10.1213/01.ANE.0000113240 .09354.E9

147. Reiter RJ, Tan DX, Kim SJ, Cruz MHC (2014) Delivery of pineal melatonin to the brain and SCN: role of canaliculi, cerebrospinal fluid, tanycytes and Virchow-Robin perivascular spaces. Brain Struct Funct 219:1873-1887. https://doi.org/10.1007/s0042 9-014-0719-7

148. Rennels ML, Gregory TF, Blaumanis OR, Fujimoto K, Grady PA (1985) Evidence for a "paravascular" fluid circulation in the mammalian central nervous system, provided by the rapid distribution of tracer protein throughout the brain from the subarachnoid space. Brain Res 326:47-63. https://doi.org/10.1016/00068993(85)91383-6

149. Di Rocco C, McLone DG, Shimoji T, Raimondi AJ (1975) Continuous intraventricular cerebrospinal fluid pressure recording in hydrocephalic children during wakefulness and sleep. J Neurosurg 42:683-689. https://doi.org/10.3171/jns.1975.42.6.0683

150. Rosenberg GA, Kyner WT, Estrada E (1980) Bulk flow of brain interstitial fluid under normal and hyperosmolar conditions. Am J Physiol 238:F42-F49

151. Schielke GP, Betz AL (1992) Electrolyte transport. In: Bradbury MWB (ed) Physiology and pharmacology of the blood-brain barrier. Springer, Berlin, pp 221-243

152. Schwartz WJ, Reppert SM (1985) Neural regulation of the circadian vasopressin rhythm in cerebrospinal fluid: a pre-eminent role for the suprachiasmatic nuclei. J Neurosci 5:2771-2778

153. Seckl J, Lightman S (1988) Cerebrospinal fluid neurohypophysial peptides in benign intracranial hypertension. J Neurol Neurosurg Psychiatry 51:1538-1541. https://doi.org/10.1136/ jnnp.51.12.1538 
154. Serrano-Pozo A, Frosch MP, Masliah E, Hyman BT (2011) Neuropathological alterations in Alzheimer disease. Cold Spring Harb Perspect Med 1:a006189. https://doi.org/10.1101/cshpe rspect.a006189

155. Shirai $Y$ (1921) On the transplantation of the rat sarcoma in adult heterogeneous animals. Japan Med World 1:14-15

156. Shively SB, Horkayne-Szakaly I, Jones RV, Kelly JP, Armstrong RC, Perl DP (2016) Characterisation of interface astroglial scarring in the human brain after blast exposure: a post-mortem case series. Lancet Neurol 15:944-953. https://doi.org/10.1016/S1474 -4422(16)30057-6

157. Silverberg GD, Heit G, Huhn S, Jaffe RA, Chang SD, BronteStewart H, Rubenstein E, Possin K, Saul TA (2001) The cerebrospinal fluid production rate is reduced in dementia of the Alzheimer's type. Neurology 57:1763-1766. https://doi.org/10.1212/ WNL.57.10.1763

158. Sixt M, Engelhardt B, Pausch F, Hallmann R, Wendler O, Sorokin LM (2001) Endothelial cell laminin isoforms, laminins 8 and 10, play decisive roles in T cell recruitment across the bloodbrain barrier in experimental autoimmune encephalomyelitis. J Cell Biol 153:933-945. https://doi.org/10.1083/jcb.153.5.933

159. Skinner DC, Malpaux B (1999) High melatonin concentrations in third ventricular cerebrospinal fluid are not due to Galen vein blood recirculating through the choroid plexus. Endocrinology 140:4399-4405. https://doi.org/10.1210/endo.140.10.7074

160. Slats D, Claassen JAHR, Spies PE, Borm G, Besse KTC, van Aalst W, Tseng J, Sjögren MJC, Olde Rikkert MGM, Verbeek MM (2012) Hourly variability of cerebrospinal fluid biomarkers in Alzheimer's disease subjects and healthy older volunteers. Neurobiol Aging 33:831.e1-831.e9. https://doi.org/10.1016/j. neurobiolaging.2011.07.008

161. Smith AJ, Jin B, Verkman AS (2015) Muddying the water in brain edema? Trends Neurosci 38:1-2. https://doi.org/10.1016/j. tins.2015.04.006

162. Smith AJ, Yao X, Dix JA, Jin B, Verkman AS (2017) Test of the "glymphatic" hypothesis demonstrates diffusive and aquaporin4-independent solute transport in rodent brain parenchyma. Elife. https://doi.org/10.7554/eLife.27679

163. Sotiriou S, Gispert S, Cheng J, Wang Y, Chen A, HoogstratenMiller S, Miller GF, Kwon O, Levine M, Guttentag SH, Nussbaum RL (2002) Ascorbic-acid transporter Slc23a1 is essential for vitamin $\mathrm{C}$ transport into the brain and for perinatal survival. Nat Med 8:514-517. https://doi.org/10.1038/nm0502-514

164. Spector R (2014) Vitamin transport diseases of brain: focus on folates, thiamine and riboflavin. Brain Disord Ther 3:120

165. Spector R, Johanson CE (2014) The nexus of vitamin homeostasis and DNA synthesis and modification in mammalian brain. Mol Brain 7:3. https://doi.org/10.1186/1756-6606-7-3

166. Spector R, Keep RF, Snodgrass SR, Smith QR, Johanson CE (2015) A balanced view of choroid plexus structure and function: focus on adult humans. Exp Neurol 267:78-86. https://doi. org/10.1016/j.expneurol.2015.02.032

167. Stevenson PG, Hawke S, Sloan DJ, Bangham CR (1997) The immunogenicity of intracerebral virus infection depends on anatomical site. J Virol 71:145-151

168. Strbian D, Kovanen PT, Karjalainen-Lindsberg M-L, Tatlisumak T, Lindsberg PJ (2009) An emerging role of mast cells in cerebral ischemia and hemorrhage. Ann Med 41:438-450. https:// doi.org/10.1080/07853890902887303

169. Stylianopoulou F, Herbert J, Soares MB, Efstratiadis A (1988) Expression of the insulin-like growth factor II gene in the choroid plexus and the leptomeninges of the adult rat central nervous system. Proc Natl Acad Sci USA 85:141-145. https://doi. org/10.1073/pnas.85.1.141
170. Sweetman B, Linninger AA (2011) Cerebrospinal fluid flow dynamics in the central nervous system. Ann Biomed Eng 39:484-496. https://doi.org/10.1007/s10439-010-0141-0

171. Syková E, Nicholson C (2008) Diffusion in brain extracellular space. Physiol Rev 88:1277-1340. https://doi.org/10.1152/physr ev.00027.2007

172. Szentistványi I, Patlak CS, Ellis RA, Cserr HF (1984) Drainage of interstitial fluid from different regions of rat brain. Am J Physiol 246:35-44

173. Taipale J, Keski-Oja J (1997) Growth factors in the extracellular matrix. FASEB J 11:51-59

174. Tan DX, Manchester LC, Reiter RJ (2016) CSF generation by pineal gland results in a robust melatonin circadian rhythm in the third ventricle as an unique light/dark signal. Med Hypotheses 86:3-9. https://doi.org/10.1016/j.mehy.2015.11.018

175. Tasker RC, Acerini CL (2014) Cerebral edema in children with diabetic ketoacidosis: vasogenic rather than cellular? Pediatr Diabetes 15:261-270. https://doi.org/10.1111/pedi.12153

176. Thal DR, Grinberg LT, Attems J (2012) Vascular dementia: different forms of vessel disorders contribute to the development of dementia in the elderly brain. Exp Gerontol 47:816-824. https:// doi.org/10.1016/j.exger.2012.05.023

177. Thorne RG (2014) Primer on central nervous system structure/ function and the vasculature, ventricular system, and fluids of the brain. In: Hammarlund-Udenaes M, de Lange E, Thorne RG (eds) Drug delivery to the brain. Physiological concepts, methodologies and approaches. Springer, New York, pp 685-707

178. Thorne RG, Hrabetová S, Nicholson C (2004) Diffusion of epidermal growth factor in rat brain extracellular space measured by integrative optical imaging. J Neurophysiol 92:3471-3481. https ://doi.org/10.1152/jn.00352.2004

179. Thorne RG, Lakkaraju A, Rodriguez-Boulan E, Nicholson C (2008) In vivo diffusion of lactoferrin in brain extracellular space is regulated by interactions with heparan sulfate. Proc Natl Acad Sci USA 105:8416-8421. https://doi.org/10.1073/pnas.07113 45105

180. Thorne RG, Nicholson C (2006) In vivo diffusion analysis with quantum dots and dextrans predicts the width of brain extracellular space. Proc Natl Acad Sci USA 103:5567-5572. https:// doi.org/10.1073/pnas.0509425103

181. Thorne RG, Pronk GJ, Padmanabhan V, Frey WH (2004) Delivery of insulin-like growth factor-I to the rat brain and spinal cord along olfactory and trigeminal pathways following intranasal administration. Neuroscience 127:481-496. https:// doi.org/10.1016/j.neuroscience.2004.05.029

182. Tietz S, Engelhardt B (2015) Brain barriers: crosstalk between complex tight junctions and adherens junctions. J Cell Biol 209:493-506. https://doi.org/10.1083/jcb.201412147

183. Tricoire H, Locatelli A, Chemineau P, Malpaux B (2002) Melatonin enters the cerebrospinal fluid through the pineal recess. Endocrinology 143:84-90. https://doi.org/10.1210/ endo.143.1.8585

184. Valdinocci D, Radford RAW, Siow SM, Chung RS, Pountney DL (2017) Potential modes of intercellular $\alpha$-synuclein transmission. Int J Mol Sci. https://doi.org/10.3390/ijms18020469

185. Wagner HJ, Pilgrim C, Brandl J (1974) Penetration and removal of horseradish peroxidase injected into the cerebrospinal fluid: role of cerebral perivascular spaces, endothelium and microglia. Acta Neuropathol 27:299-315. https://doi. org/10.1007/BF00690695

186. Weed L (1914) Studies on cerebro-spinal fluid. No. IV: the dual source of cerebro-spinal fluid. J Med Res 31:93-118

187. Welch K (1963) Secretion of cerebrospinal fluid by choroid plexus of the rabbit. Am J Physiol 205:617-624

188. Weller RO, Kida S, Zhang ET (1992) Pathways of fluid drainage from the brain-morphological aspects and immunological 
significance in rat and man. Brain Pathol 2:277-284. https:// doi.org/10.1111/j.1750-3639.1992.tb00704.x

189. Weller RO, Subash M, Preston SD, Mazanti I, Carare RO (2008) Perivascular drainage of amyloid-beta peptides from the brain and its failure in cerebral amyloid angiopathy and Alzheimer's disease. Brain Pathol 18:253-266. https://doi.org /10.1111/j.1750-3639.2008.00133.x

190. Winkler EA, Minter D, Yue JK, Manley GT (2016) Cerebral edema in traumatic brain injury: pathophysiology and prospective therapeutic targets. Neurosurg Clin N Am 27:473-488. https://doi.org/10.1016/j.nec.2016.05.008

191. Wolak DJ, Pizzo ME, Thorne RG (2015) Probing the extracellular diffusion of antibodies in brain using in vivo integrative optical imaging and ex vivo fluorescence imaging. $\mathbf{J}$ Control Release 197:78-86. https://doi.org/10.1016/j.jconr el.2014.10.034

192. Wolak DJ, Thorne RG (2013) Diffusion of macromolecules in the brain: implications for drug delivery. Mol Pharm 10:14921504. https://doi.org/10.1021/mp300495e

193. Woollam DHM, Millen JW (1954) Perivascular spaces of the mammalian central nervous system. Biol Rev 29:251-283. https ://doi.org/10.1111/j.1469-185X.1954.tb00597.x

194. Wu C, Ivars F, Anderson P, Hallmann R, Vestweber D, Nilsson P, Robenek H, Tryggvason K, Song J, Korpos E, Loser K, Beissert S, Georges-Labouesse E, Sorokin LM (2009) Endothelial basement membrane laminin alpha5 selectively inhibits T lymphocyte extravasation into the brain. Nat Med 15:519-527. https://doi. org/10.1038/nm.1957
195. Xie L, Kang H, Xu Q, Chen MJ, Liao Y, Thiyagarajan M, O'Donnell J, Christensen DJ, Nicholson C, Iliff JJ, Takano T, Deane R, Nedergaard M (2013) Sleep drives metabolite clearance from the adult brain. Science 342:373-377. https://doi. org/10.1126/science. 1241224

196. Yao X, Hrabetova S, Nicholson C, Manley GT (2008) Aquaporin4-deficient mice have increased extracellular space without tortuosity change. J Neurosci 28:5460-5464. https://doi.org/10.1523/ JNEUROSCI.0257-08.2008

197. Zabel MD, Reid C (2015) A brief history of prions. Pathog Dis 73. https://doi.org/10.1093/femspd/ftv087

198. Zafeiriou DI, Batzios SP (2013) Brain and spinal MR imaging findings in mucopolysaccharidoses: a review. Am J Neuroradiol 34:5-13. https://doi.org/10.3174/ajnr.A2832

199. Zervas NT, Liszczak TM, Mayberg MR, Black PM (1982) Cerebrospinal fluid may nourish cerebral vessels through pathways in the adventitia that may be analogous to systemic vasa vasorum. J Neurosurg 56:475-481. https://doi.org/10.3171/ jns.1982.56.4.0475

200. Zhang ET, Inman CB, Weller RO (1990) Interrelationships of the pia mater and the perivascular (Virchow-Robin) spaces in the human cerebrum. J Anat 170:111-123

201. del Zoppo GJ, Milner R (2006) Integrin-matrix interactions in the cerebral microvasculature. Arterioscler Thromb Vasc Biol 26:1966-1975. https://doi.org/10.1161/01.ATV.0000232525 $.65682 . \mathrm{a} 2$ 